\title{
Transcoding the I Ching as Composition Techniques in Chou Wen Chung, Zhao Xiaosheng and Chung Yiu Kwong
}

\author{
Ke, XUE (College of Humanities, Beibu Gulf University, China)
} shengguadanzi@163.com

Fung Ying, LOO (Cultural Centre, University of Malaya, Malaysia)

loofy@um.edu.my

\begin{abstract}
Composers such as Chou Wen Chung, John Cage, Zhao Xiaosheng, Chen Yi, Isang Yun, Chung Yiu Kwong and Fang Xiaomin are among the many who have been inspired by the idealism of the I Ching or Book of Change, which embodies mathematics, philosophy, astronomy and divination. In this paper, three Western trained composers, Chou Wen Chung, Zhao Xiaosheng and Chung Yiu Kwong, who are the figures of Chinese new music with the manners of overseas Chinese domain, China mainland and Hong Kong-Taiwan respectively, transformed the I Ching as three new compositional systems on their different understandings. This article explains the basic principles of three works and how the composers decoded and transcoded the mystical hexagrams from an ancient metaphysical calculation of Chinese science into music. The analysis shows how the I Ching was applied as a musical theory based on different readings of the 64 hexagrams and aesthetic differences. In addition, there are similarities and differences among three works that shows a development from Chou's initiation, Zhao's innovation, and consequently Chung's complexity in their compositional design. As a summary, aesthetic and musical stylistic differences are obvious due to the three composers' musical background, although all three works demystify an ancient philosophy through creation of compositional theories. Zhao's work witnessed individuality compared to Chou's "borrow" and Chung's "transplant."
\end{abstract}

Keywords: I Ching; Compositional System; Chou Wen Chung; Zhao Xiaosheng; Chung Yiu Kwong.

\section{Transcodificando o I Ching como Técnicas de Composição em Chou Wen Chung, Zhao Xiaosheng e Chung Yiu Kwong.}

Resumo: Compositores como Chou Wen Chung, John Cage, Zhao Xiaosheng, Chen Yi, Isang Yun, Chung Yiu Kwong e Fang Xiaomin estão entre os muitos que se inspiraram nas ideias do I Ching, ou Livro das Mutações, que incorpora filosofia, matemática, astronomia e divindade. Nesse trabalho, três compositores treinados no Ocidente, Chou Wen Chung, Zhao Xiaosheng e Chung Yiu Kwong, e que são as figuras que se destacam na nova música chinesa, no exterior, na China continental, em Hong Kong e em Taiwan, respectivamente, transformaram o I Ching em três novos sistemas de composição, cada um à sua maneira. Esse artigo explica os princípios básicos dos três composições e como eles decodificaram e transformaram os hexagramas místicos, que são provenientes de um cálculo metafísico da ciência chinesa, em música. Essa análise mostra como o I Ching foi aplicado como uma teoria musical baseada nas diferentes maneiras de ler os 64 hexagramas e seus diferentes estilos. Além disso, as semelhanças e diferenças entre os três trabalhos mostram o desenvolvimento da iniciação de Chou, a inovação de Zhao e, consequentemente, a complexidade de Chung em suas composições. Em resumo, as diferenças de estilos estéticos e musicais são óbvias, levando em consideração a experiência musical dos três compositores, embora as três obras desmistifiquem uma antiga filosofia através da criação de teorias composicionais. O trabalho de Zhao lidou com a individualidade, quando comparado ao "empréstimo" trabalhado por Chou e ao "transplante” trabalhado por Chung.

Palavras-chave: I Ching; Sistemas Composicionais; Chou Wen Chung; Zhao Xiaosheng; Chung Yiu Kwong.

As the fountainhead of Chinese culture and the initiation of the Hundred Schools of Thought, the I Ching (易经, Book of Changes) has played a decisive role in China (ZENG, 2009). In addition, more progressive and advanced science and technology have verified the concepts of the mystical I Ching, such as Gottfried Wilhelm von Leibnitz's binary calculus, which coincided with the position and sequence of the 64 hexagrams and pioneered the theory of modern computers (LACH, 1945; RYAN, 1996). Nevertheless, a growing global interest in research from other disciplines explored into the application of I Ching in science (see CHEN, 2017; LU; PANG; WOO, 2005) and arts (CHANG, 2011; LOO \& LOO, 2012, 2013). Applied I Ching metaphysics into other disciplines diverged itself from a unilateral understanding that the I Ching is merely a tool of divination. 
The I Ching, also called Zhou Yi (周易), is all-encompassing: as Lvshi Chunqiu (吕 氏春秋, Lv's Spring and Autumn Annals) notes, the supreme macrocosm has no boundary, whereas the extreme microcosm has no core (其大无边, 其小无内). It is rooted in the eight trigrams created by Fu Xi ${ }^{1}$ (2953-2838 BC) for the purpose of meteorology. During the Zhou dynasty, King Wen (文王) and his son, Jidan (姬旦), the Duke of Zhou, superimposed the eight trigrams to produce 64 hexagrams and translated them into text. The interpretation of the I Ching was not completed until the end of the Spring and Autumn Periods, when Shiyi (十翼, Ten Wings) ${ }^{2}$, or Explanation of Yi Zhuan (易传, I Ching), was written by Confucius. Later, the Hundred Schools of Thought, including Taoism, the Yin-Yang School and Mohism, all extended the philosophy of the I Ching in practice. Therefore, the I Ching is also a crystallization of collective wisdom (ZENG, 2009).

Xicizhuan (系辞传, Commentary on the Appended Phrases) explained that myriad things, or Tai Chi, are constructed by yin and yang in the theory of the I Ching, which are represented by yinyao (阴爻, broken line) “--” and yangyao (阳爻, unbroken line) “ - ”. Based on the yin and yang, four images produce laoyin (老阴, pure yin) =:, shaoyang (少 阳, transformation from yang to yin) $=$, laoyang (老阳, pure yang) $=$, and shaoyin (少阴, transformation from yang to yin) $=$. However, the four images only imply the Heaven and Earth, excluding human beings and other creative forces within them. Therefore, Fu Xi observed the world and added one line on four symbols to produce eight trigrams: Qian ( 乾, Heaven) 三, Dui (兑, Lake) 三, Li (离, Fire) 玉, Zhen (震, Thunder) 玉, Xun (巽, Wind) 三, Kan (坎, Rain) =-, Gen (艮, Mountain) 玉 and Kun (坤, Earth) 玉:. The three lines of the eight trigrams symbolized Earth, humans and heaven from bottom to top. Sixty-four hexagrams were derived from superimpositions of the eight trigrams in dyads.

The application of the I Ching has cultivated interest in examining multi-mode compositions in the music industry: the divination of the I Ching inspired John Cage's chance music (AU, 2013; JENSEN, 2009), yin and yang theory affected Isang Yun's music's dynamics, rhythms, intensions and other aspects of this work (KIM, 2011), and the concept of Wu Xing (五行, Five Phases) from the I Ching is found in the Wu Xing compositional theory of Fang Xiaomin (Zidong WANG, 2013). In addition to embodying compositional theories, the works that reflect the I Ching are outstanding, namely, Chen Yi's Ba Ban (2000) for piano, Carlo Domeniconi’s Yi Jing (I Ching) (2003) for guitar, Chen Qigang's Wu Xing (1998) for orchestra, Zhu Jianer's He (和, synthesis) (1992) for traditional instrumental quintets, and Per Nørgård's percussion solo I Ching (1982) (LI, 2003; ZHAO, 2014; ZHAO, 2010; ZHU, 1995).

In Rao's (2002) view, applying the I Ching in music is a way to associate traditional Chinese elements with Western Serialism theory in contemporary composers' expressions, accordingly, Chou Wen Chung (周文中, b. 1923), Zhao Xiaosheng (赵晓生, b.1945) and Chung Yiu Kwong (钟耀光, b.1956) are regarded as the composers whose creations resonate with Rao's vision. In addition, Chou, Zhao and Chung are the representative figures of Chinese new music, whose theories to some extent represent the manners of overseas Chinese domain, China mainland and Hong Kong-Taiwan respectively.

In strengthening China during the Second Opium War dominated Qing dynasty, the official Zhang Zhidong's slogan "Chinese learning for the fundamental principles, Western learning for practical application" has delivered a huge influence to the sciences, education and democracy since 1885 (WU; HAN, 2014). The philosophical context influenced an active adaptation of Western music during the $20^{\text {th }}$ century in China, that marked a drastic change compared to the lack of reception of Western music during the $17^{\text {th }}$ and $18^{\text {th }}$ century (LAU, 2017). Unlike Chinese traditional and folk music, Liu (2009) commented that the 
Chinese New Music of that time represents cultural simulacra of a transition period for Chinese composers with euro-centric music of neo-romanticism and classicism, such as Wang Jianzhong's Hundreds Birds Worshipping The Phoenix, Chu Wanghua's The Moon Over A Fountain and Zhao's Fisherman Song (ZHOU, 2007; XUE; LOO, 2017).

Chou Wen Chung, along with young generation composers such as Tan Dun, Chen Yi, Bright Sheng, and Qu Xiaosong who studied abroad in the late half of 1980s and immigrated abroad later, delivered a fusion of modern Western compositional techniques with Chinese musical elements that is more familiar to a Western ear. Thus, the phenomenon invites questions of identity in the academia (LAU, 2017). Composers such as Wu Zuqing (吴祖强, b.1927), Jin Xiang (金湘, b.1935), Wang Xilin (王西麟, b.1937), Yang Liqing (杨 立青, b. 1942), and Zhao Xiaosheng, upon their return to mainland China, aim at writing composition that features Chinese aesthetics in meeting with the local market and demand. Thus, these returnees' works conformed to a much more obvious Chinese identity and aesthetic.

On the other hand, there was an absent of home breed composer in Hong Kong during the British colonial period. Since 1945, influence from China mainland composer led to an emergence of a group of composers such as Lin Sheng Xi (林声翕, b. 1914) and Hung You Di (黄友棣, b. 1912) (LIU, 2009). While the first introduction of Western art music to Taiwan was traced back to the arrival of missionaries in the $17^{\text {th }}$ century, rather similar to the mainland. Taiwan then was occupied by Japan after First Sino-Japanese War in 1985, where Taiwanese composers studied in Japan for Western compositional techniques. In the 1970s, many of the younger generation composers chose to further their study in Europe or the United States (TSAI, 2017). Chung Yiu Kwong, a Hong Kong-born composer, moved to Taiwan in 1991, was regarded as one of the $4^{\text {th }}$ generation composers in Taiwan ${ }^{3}(\mathrm{H}$. J. CHEN, 2008). Chung's compositions have a distinct modern musical characters of Taiwan and Hong Kong. Therefore, a comparative research of Chou, Zhao and Chung, in terms of transcoding the I Ching in their music lends a comprehensive lens for Chinese new music.

The theoretical frameworks based on the I Ching weaved by Chou, Zhao and Chung, without a doubt, showed a new perception of Chinese traditional culture injected in the examination of the West and East. These theories caught scholars' attentions such as Chang (1995) whom looked into Chou's musical development and the stage of the I Ching embodied in this work. Lai (1997) and Wang (2013), in addition, analyzed Chou's Variable Modes in Metaphors (1960), Cursive (1963) and Pien (1966) and concluded that he was a pioneer in transforming metaphysics into concrete and pithy musical works. Depending on the traditional philosophy and aesthetics, Chen (2006) looked into the Variable Modes through the example of Windswept Peaks (1990), a recent work, and revealed Chou's musical language in his mature period. Zhao Xiaosheng (1990, 2006) and Chung Yiu Kwong (1995) authored Tai Chi (Composition System) ${ }^{4}$ and I Ching (Compositional System) about their compositional concepts. The influence of Tai Chi (Compositional System) is considerable, it was regarded as a breakthrough of modern Chinese compositional theory (BIAN, 1996; M. CHEN, 1988; KOUWENHOWEN, 1992; LIU, 2010). Besides that, Tai Chi (Compositional System) was analyzed from diversity of perspectives; Ma (2013) compared Zhao's theory to Allen Forte with regard to both the pitch class and its periodic table, whereas Shi (2012) explained the theory of the Tai Chi (Composition System) by analyzing representative works. Comparing with Chou and Zhao's works, the previous research regarding Chung's I Ching (Compositional System) seems a little rare.

A retrospection of past literatures may contribute significantly in a micro-analytical view of each composer's I Ching system, almost none is related to compare with three of 
them, except for scholar Sau's discussion. However, Sau (2013) only compared the works of Chou and Zhao with John Cage's, somehow weaken its arguments as there are obvious difference between the two Chinese composers and Cage, where the latter applied only the divination characteristics of the I Ching. Therefore, in reviewing the development of Chinese composer's works of I Ching, a scenario of blind men and the elephant may invite a macro-lens in analyzing all three composers Chou, Zhao and Chung in terms of their similarities and differences, the aim of this paper attempts to find out. The calculation of pitch sets ${ }^{5}$, analysis of three systems and interview with composers, formed the basis of the discussion in this paper; looking into the common traits of the composers' background with musical training from the West (United States) and their Chinese identity rooted in different domains in the development of Chinese new music.

\section{Chou Wen Chung's Variable Modes}

Chou Wen Chung, originated from Shandong province of China, he furthered his study in Guangxi University and Chongqing University successively during World War II, and finally received his B. S. degree in architecture at Chongqing University. In 1946, Chou continued his study in architecture with a scholarship from Yale University, however, the enthusiasm for music drove him to drop out of architecture and to study violin as first major as well as composition as second, in the New England Conservatory of Music. Nicolas Slonimsky became the main influence in encouraging Chou towards fusion between Chinese and Western music. However, during Chou's days in New York, Bohuslav Martinu's teaching enlightened Chou that he could not merely incorporate Chinese soundscape into a Western context referring to his pentatonic arrangement of a Bach's fugue. On the other hand, it was Edgar Varèse whom became the most important mentor and friend to Chou that influenced the composer's individual stylistic formation in terms of compositional techniques, sound aesthetics, that led to independence and innovation in composition (CHANG, 2006). Therefore, these led to Chou's mature and individual compositional techniques, theories and ideals in his later life.

Chou was particularly drawn to culture and musical fusion of the East and West in his late 30s, thus created an elaborated pitch system based on the I Ching eight trigrams and named it Variable Modes (or Pien modes; hereinafter VM) (LAI, 2009). Although Chou's liaisons with I Ching was rooted in his family background that traced back to Zhou Dunyi, a Confucian scholar of the Song dynasty who embedded I Ching into Confucian doctrine and his father too, was a practitioner of I Ching prognostication (KWAN, 2003); however, it was Nicholas Slonimsky, who encouraged Chou to highlight his Chinese identity as a mean to success in the Western music industry.

In Chou's (2010) own account, the ideas of VM began in the early 1940s when he was exploring pluralistic musical forms such as the pentatonic modal system, Tang Dynasty secular music, medieval theory, and even Greek theory, which laid the foundation for musical mergence in practice and a better understanding of the history of Chinese music. Subsequently, he continued to search for more Chinese musical modes and tuning system along with influence of modern theories and practices. Eventually, the influence of both East and West complicated the composer's poiesis state of mind where Chou was undecided in to what limit he should incorporate musical elements from the East. In his personal website, he mentioned the contradiction between deciding the complexity of the Indian raga and Chinese qin. 
By the end of the 1950s, Chou found the I Ching as the core of his inspiration and subsequently in the early 1960s, he pioneered VM that continues to present in his later compositional stages (CHANG, 1995). The eight trigrams play an important role in Chou's VM, the binary numbers of which construct the three types of relationships, namely, inverted relation, yin-yang interchanged relation, and the combined relation (Tab. 1):

\begin{tabular}{|c|c|c|c|}
\hline Hexagrams & Mountain & \multirow{3}{*}{ Invert to } & Thunder \\
\hline Symbol & $\Xi$ & & 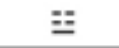 \\
\hline Numbers & 001 & & 100 \\
\hline Hexagrams & Mountain & \multirow{3}{*}{ Interchange to } & Lake \\
\hline Symbol & $\Xi$ & & $\dddot{\equiv}$ \\
\hline Numbers & 001 & & 110 \\
\hline Hexagrams & Mountain & \multirow{3}{*}{ Invert and interchange to } & Wind \\
\hline Symbol & $\Xi$ & & $\equiv$ \\
\hline Numbers & 001 & & 011 \\
\hline
\end{tabular}

Tab. 1: Chou Wen Chung's eight modes corresponding eight trigrams

Based on the symbols of the eight trigrams that consist of three lines, Chou divided the twelve-tone into three portions according to third-relations, or trichotomies, which are three conjuncts of C-E, E-G\#, G\#-C in the ascending scale and C-Ab, Ab-E, E-C in the descending scale (Ex. 1). Similar to the meaning of the three lines in eight trigrams, Chou's trichotomy represents the earth, humans and heaven from bottom to top; in other words, it signifies C-E and C-Ab for earth, E-G\# and Ab-E for humans, and G\#-C and E-C for heaven. Seen from this division, the translation of trigrams into music shows the application of the concept of sancai (三才, Designation of heaven, Earth and human beings) ${ }^{6}$ with each major third representing an attribute and simultaneously following the order of Earth, humans and heaven to the corresponding symbol of the trigram.

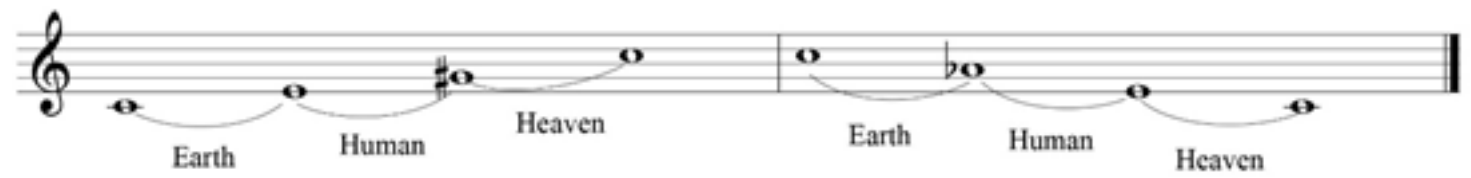

Ex. 1: A twelve-tone that is divided into three conjunctions in ascending and descending order.

Based on the trichotomy framework, there are four minor seconds in a major third or conjunct. Thus, Chou presents two forms to construct the modes that contain the yinyang relationship reflected in the trigram symbol; the broken line is represented by two major seconds and the unbroken line is a minor third plus a minor second. According to this formula, the eight modes, or prototypes, shown in Ex. 2 are produced following the different permutations of lines in eight trigrams. 


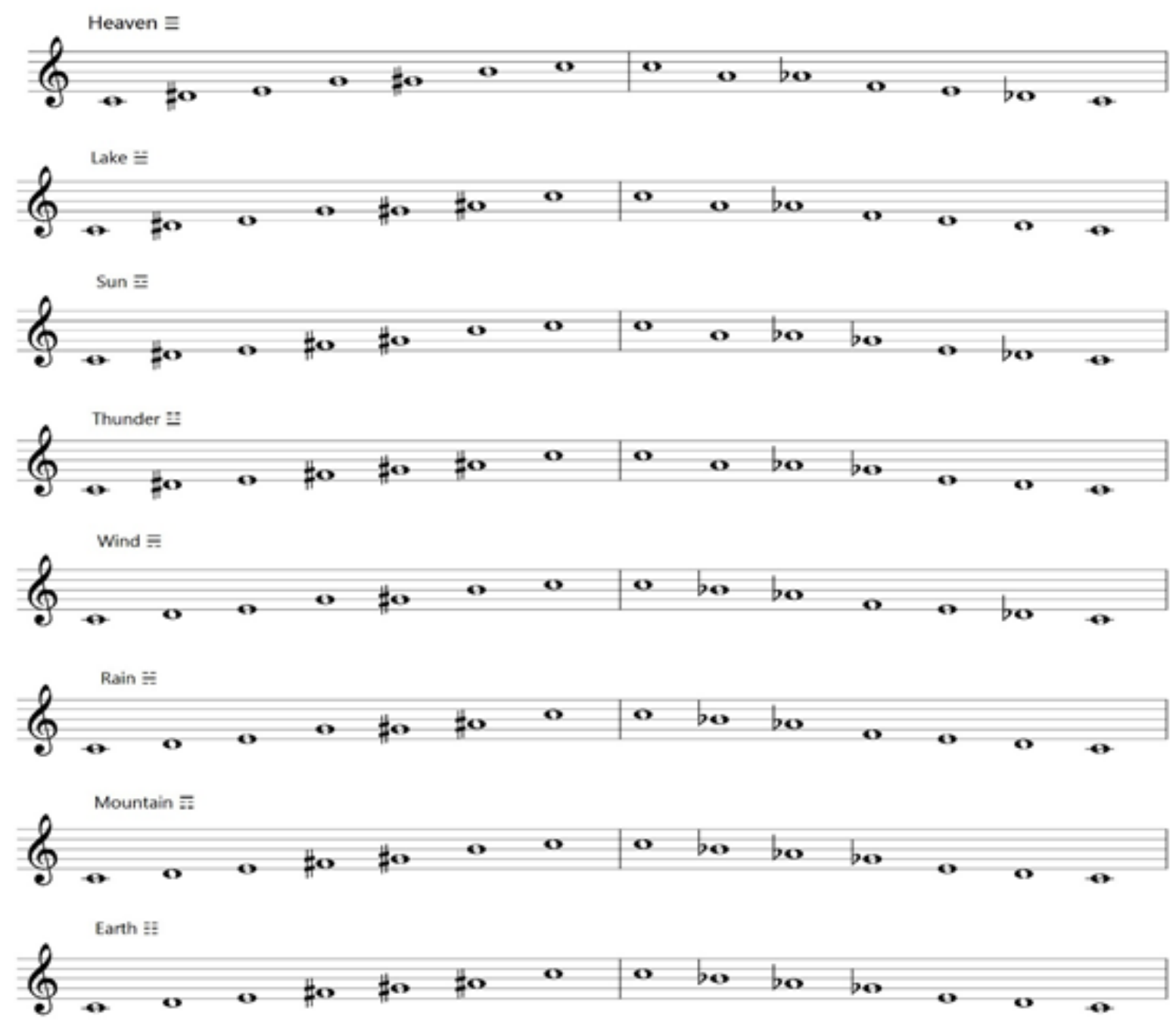

Ex. 2: Eight modes corresponding eight trigrams.

With Chou's maintenance of the aesthetics of nature (KWAN, 2003), he utilizes the eight natural phenomena that the eight trigrams indicate to embody VM, rather than the names of the eight trigrams, which are shown as Tab. 2 .

\begin{tabular}{|c|c|c|c|}
\hline Eight trigrams & Trigram image & Image in nature & VM \\
\hline Kun (㙂, the Receptive) & $\Xi$ & Earth & Earth \\
\hline Gen (艮, Keeping Still) & $\Sigma$ & Mountain & Mountain \\
\hline Kan (坆, the Abysmal) & $\ddot{z}$ & Water & Rain $^{7}$ \\
\hline Xun (㖺, the Gentle) & $\equiv$ & Wind & Wind \\
\hline Zhen (震, the Arousing) & $\Xi$ & Thunder & Thunder \\
\hline Li (离, the Clinging) & $\equiv$ & Fire & $\operatorname{Sun}^{8}$ \\
\hline Dui (兑, the Joyous) & $\dddot{\Xi}$ & Lake & Lake \\
\hline Qian (乾, the Creative) & $\equiv$ & Heaven & Heaven \\
\hline
\end{tabular}

Tab. 2: Chou Wen Chung's eight modes corresponding eight trigrams. 
According to the principle of constructing 64 hexagram, each of which superimposes two eight trigrams, the scales can be amplified into a compound form that represents the characters of the 64 hexagrams. However, there are three limitations: 1) the order of the direction, which includes both ascending and descending; 2) the pitches in the two modes, which are a minor second apart, such as $\mathrm{C}$ and $\mathrm{C \#}$; and 3) some of the relationships in two modes, such as complementary or symmetrical relationships. Ex. 3 shows the combination of the Lake and Wind modes, which have a symmetrical relationship as a result of their trigram images. The ascending scale in the Lake mode reflects the structure of yang-yangyin, and the Wind mode reflects yang-yin-yin as a descending permutation. At the same time, as in the Allen Forte set class table, the hexachord scales of the Lake and Wind modes are all in the set of $6-31[0,1,3,5,8,9]$, and the Wind mode is higher by a minor second than the Lake mode. Therefore, the scales of the Lake and Wind modes also show a complementary relationship because they shape a twelve-tone.

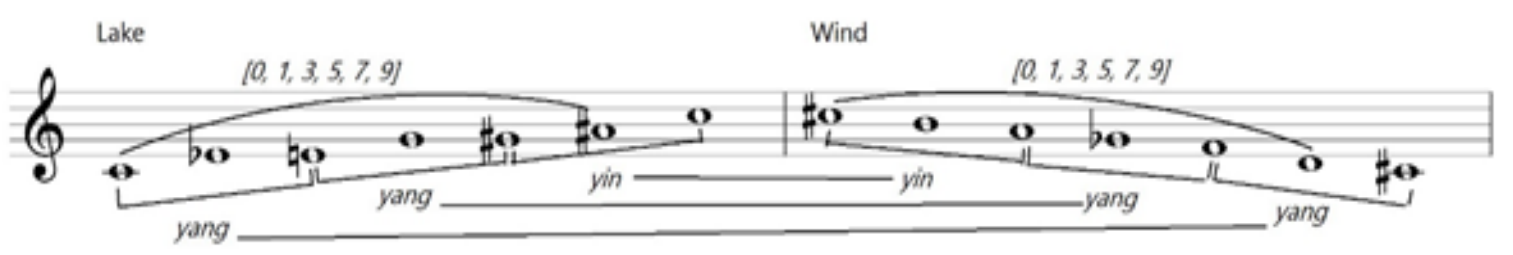

Ex. 3: The combination of the Lake and Wind modes

Similar to the combination of the Wind and Lake modes, other combinations such as Thunder and Mountain (亨), Mountain and Thunder (咅), two sun modes (豆), two rain modes (訔), two heaven modes (豆) and two Earth modes (棓) (Ex. 4), can be integrated with a twelve-tone.
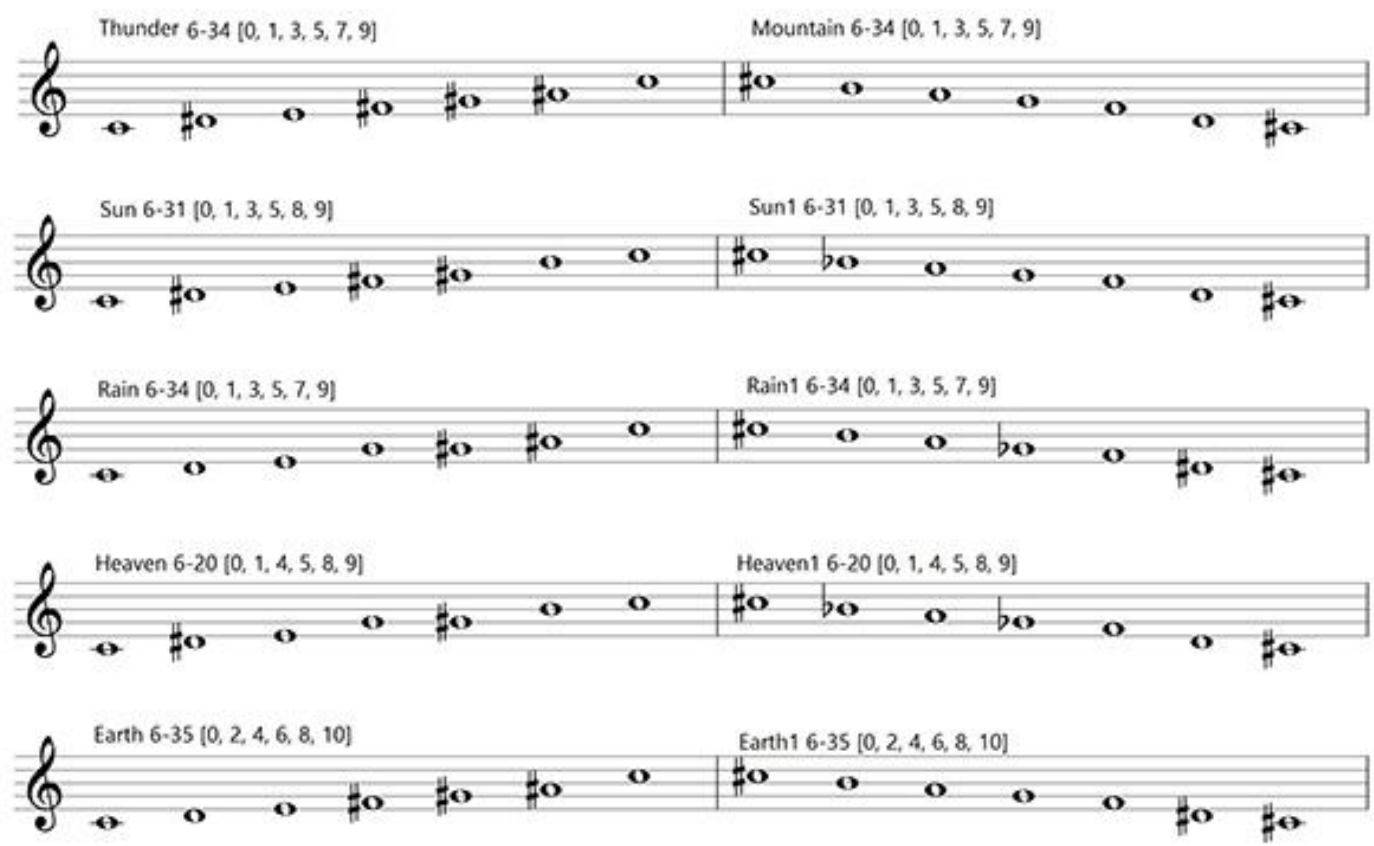

Ex. 4: The combination of pairs of modes that can be integrated with a twelve-tone. 
VM describes a concept of the Chinese character 易 (Change) of the I Ching, and Chou's works, such as Cursive (1963) and Pien (1966), which employed VM, explain this essence. Thus, although there are eight basic modes and 64 derivative modes (64 hexagrams comprised by superimposing eight trigrams in dyads), the tonal attribute is ambiguous, and the conception of the pitch-class set is obvious: it is closer to Serialism than the traditional modes and scales.

\section{Zhao Xiaosheng's Tai Chi Composition System}

The composer Zhao created a composition system name Tai Chi upon his return from the United States to China in 1980s. The I Ching inspired him as it reflects the cycle of life of continuous changes from the lowest point (or nothingness) to reaching a peak that wanes and the whole process takes place again. Based upon the cyclical Tai Chi diagram of the 64 hexagrams in I Ching drawn by Shao Yong (1011-1077) (RYAN, 1996), Zhao comprehended the philosophical ideal that everything is ever-changing with circulation, which became the foundation for recreating the Tai Chi diagram and the Tai Chi Composition System (hereinafter ICCS) (ZHAO, 2006, p. 297).

Zhao also created a Tai Chi chord, forming the base of the Tai Chi diagram and of the pitch-class sets and harmony that correspond to the 64 hexagrams (ZHAO, 2006, p. 183). Tai Chi chord works as two separate entities, as the composer stated during an interview:

The secret of TCCS is that it separates a twelve-tone into two sets, six plus six, one set consisting of C, D, E, G, A, plus F\# and the other comprising A\#, G\#, E\#, D\#, $\mathrm{C \#}$, plus $\mathrm{C}$. This means that one is a pentatonic scale that adds an additional note $\mathrm{F} \#$ as bianzhi (变徵) ${ }^{7}$, and the other is a retrograde pentatonic scale with the sharps added to additional note $\mathrm{C}$ 古 as (闰) ${ }^{8}$... These are not twelve-tones, which are twelve notes. It resonates with Chinese scales and chime-bells... I did not conclude from the chime-bells of Marquis Yi of the Zeng State (曾侯乙编钟). I obtained the results from another formula, which is right in that the one coincides with chime-bells... the most important is that the sound is different than in the West and is associated with some Chinese sound disciplines (ZHAO, 2016, translation by authors).

The issue of whether the Tai Chi chord transmits a twelve-tone or only twelve notes that resonate with a traditionally Chinese sound is analyzed below.

As the composer states, the Tai Chi chord depicts the two-part Tai Chi diagram that was first introduced by the Song dynasty philosopher and Confucian scholar Zhou Dunyi (ADLER, 2014), the forefather of Chou Wen Chung. In this chord, the black-head notes that are in the treble staff with the white-head C\# comprise the yin portion of the two-part Tai Chi diagram. In addition, the white-head notes that are in the bass staff with the black-head $\mathrm{C}$ দ comprise the yang portion (Ex. 5a), which reflects the spirit of a Tai Chi diagram in which yin includes yang and yang contains yin, along with the metamorphoses, interdependence and transmutations between yin and yang (LIN, 2008). In either the yin or the yang portion, there are six intervals (perfect $5^{\text {th }}$, minor $3^{\text {rd }}$, major $3^{\text {rd }}$, minor $2^{\text {nd }}$, major $2^{\text {nd }}$, and tri-tone) in each set; they have a mirror-image relation (Ex. 5b). 


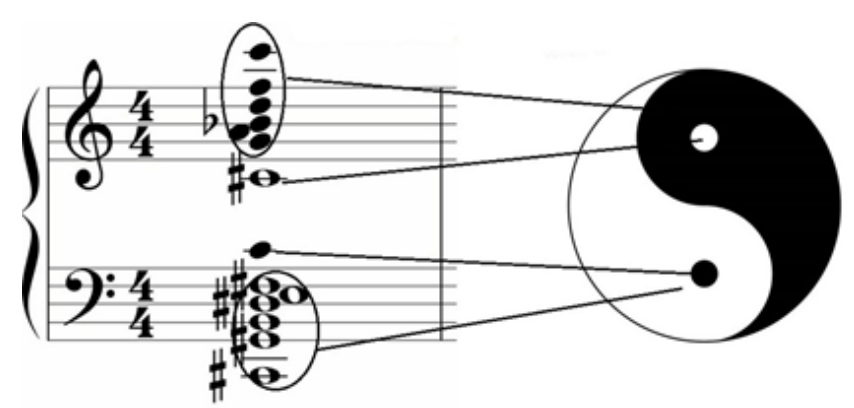

Ex. 5a: The Tai Chi chord depicts the two-part Tai Chi diagram.

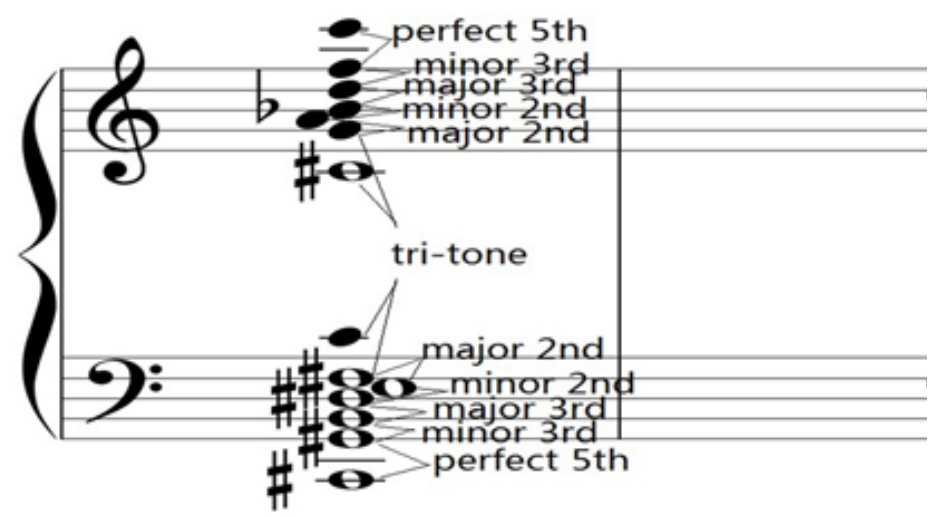

Ex. 5b: The interval contents of the Tai Chi chord.

The nature of the Tai Chi chord that is horizontal shaped a complementary twelvetone series (Ex. 6), and the yin and yang sets belong to the same pitch-class set, which is 6-32 [0, 2, 4, 5, 7, 9] and the interval vector [143250]. Therefore, it is valid to conclude that the Tai Chi scale, which comprises the notes of the Tai Chi chord with the order of the pitches from low to high register, coincides with the twelve-tone scale. In addition, the Tai Chi scale reflects a permutation of combining pentatonic scale with twelve-tone series, along with other coetaneous composers' attempts, such as Luo Zhongrong's Crossing the River to Pick Hibiscus (1980), Lu Shilin's The Family of Red-crowned Crane (1978), and Peng Zhimin's Landscape Set (1985), Gao Weijie's The Sun (1987) (WANG, 2004).

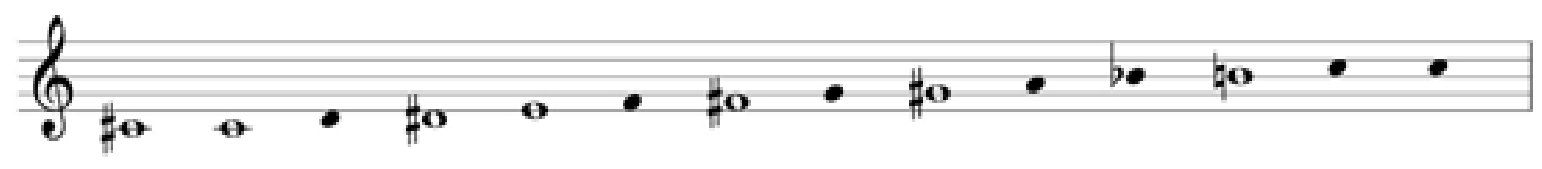

Ex. 6: The Tai Chi scale.

In terms of the four images based on Tai Chi chords, Zhao extracts two minor triads from the yin set without the $\mathrm{C}$ note and two major triads from the yang set without $\mathrm{C \#}$ to represent four images called four-image chords (Ex. 7). 


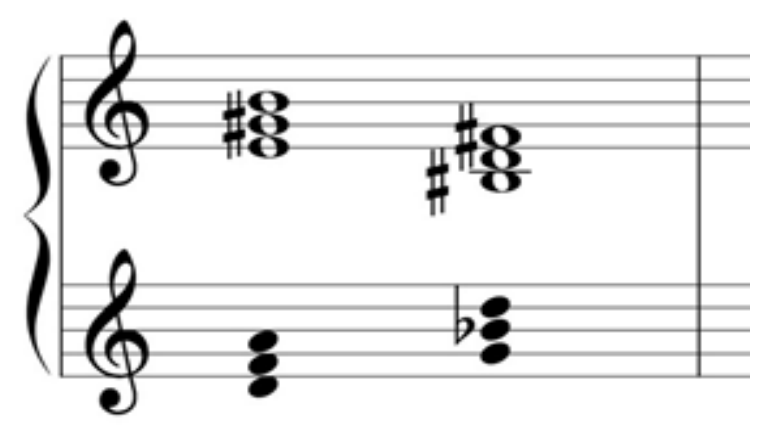

Ex. 7: Four-image chords.

The pitch-class sets of 64 hexagrams that transformed from simplicity (yin) to complexity (yang) resembles the nature law of Tai Chi in growth and decline (ZHAO, 2006, p. 185). In addition, there is a limitation of scope in the pitch-class sets calculation: 1) the pitch classes are extracted from yin and yang sets of the Tai Chi chord; 2) according to the symbols of the hexagrams, the pitch classes are matched with symbols from the bottom to top; and 3) all pitch classes that correspond to the yinyao (broken line) must be removed, and all pitch classes that correspond to the yangyao (unbroken line) of symbol must be reserved, to obtain the pitch classes of one hexagram. The adaption of the Tai Chi chord to a hexagram symbol establishes the arrangements, namely, F\# and G to chuyao (初爻, first line), E and A to eryao (二爻, second line), D\# and Bb to sanyao (三爻, third line), B and D to siyao (四爻, fourth line), G\# and F to wuyao (五爻, fifth line), and C and C\# to shangyao (上爻, upper line) (Ex. 8).

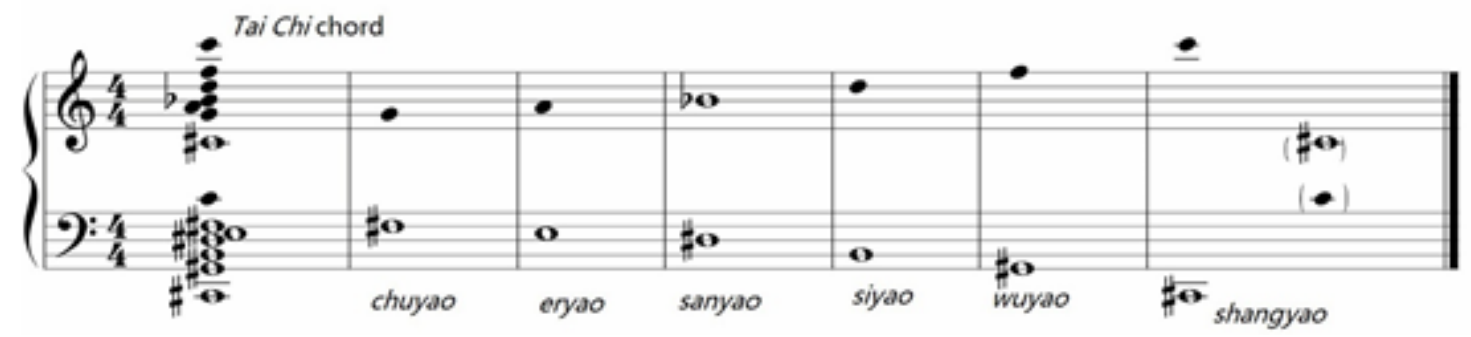

Ex. 8: The adaption of the Tai Chi chord to six lines of hexagram.

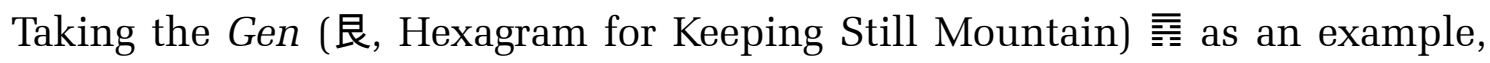
delve into the formation of pitch classes of hexagrams, the $\mathrm{D \#}, \mathrm{Bb}, \mathrm{C \#}$ and $\mathrm{C}$ that correspond with sanyao and shangyao comprise the pitch classes of Gen hexagram, following the pitch-class set calculation. With this analogy, Ex. 9 shows the entire pitch classes of the 64 hexagrams: 

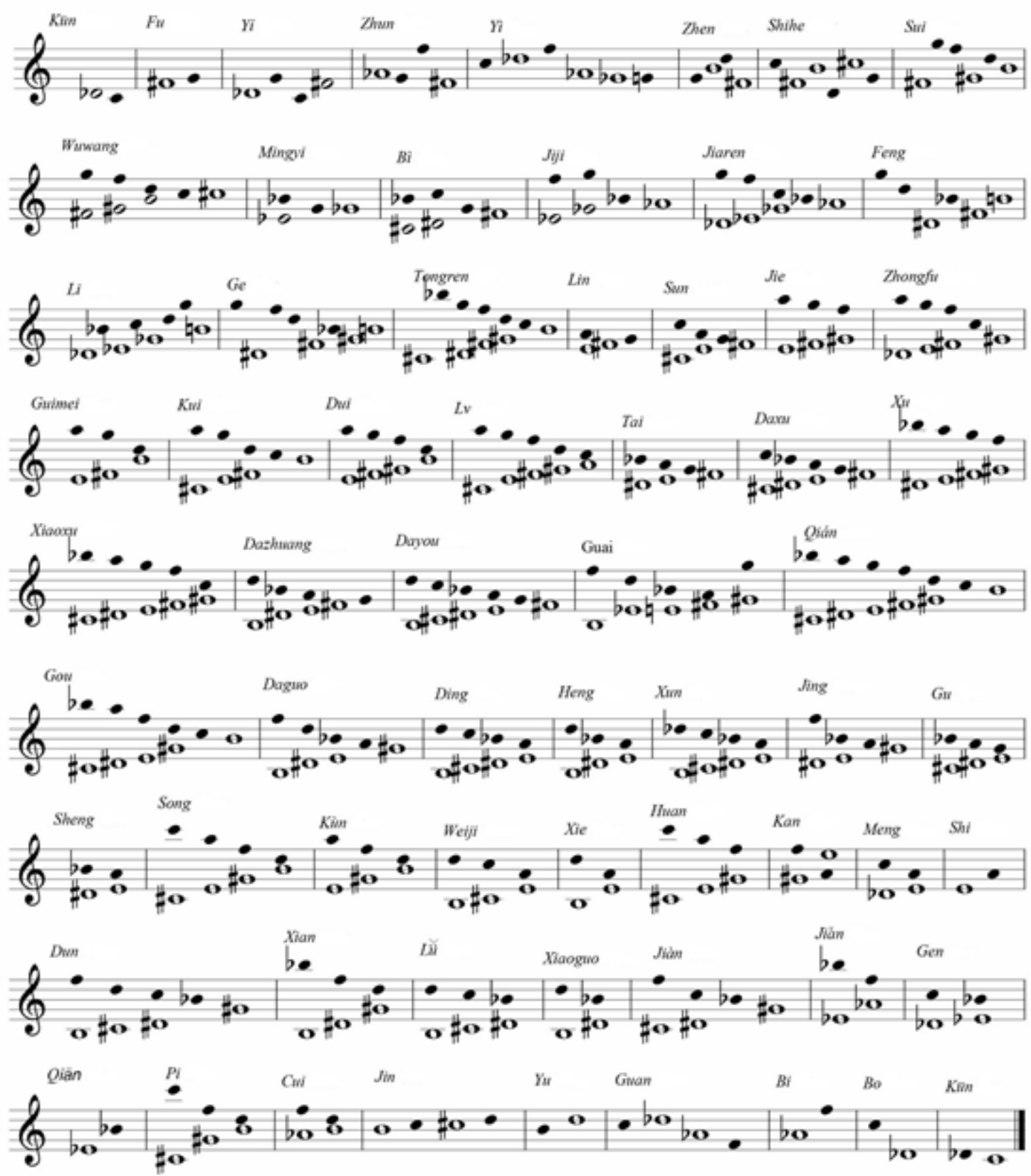

Ex. 9: The pitch-class sets of the 64 hexagrams.

Apart from the same pitch-class sets that have the same interval vectors, 64 sets of pitch classes are derived from 30 prime forms, calculated by Allen Forte's set theory. Because of the yin-yang dyads of the Tai Chi chords from which the pitch classes are extracted, the sets show an even-numbered increase, such as a dyad, a tetrachord, a hexachord, an octachord, a decachord, or a dodecachord. The following is a list of these chords:

a) Three dyads:

2-1 [0,1] <100000>: Kūn (坤, Hexagram for the Receptive Earth), Fu (复, Hexagram for Return), Bo (剥, Hexagram for Splitting Apart);

2-3 [0,3] <001000>: Yu (豫, Hexagram for Enthusiasm), Bì (比卦, Hexagram for Holding Together);

2-5 [0, 5] <000010>: Qiān (谦, Hexagram for Modesty), Shi (师, Hexagram for Army). 
b) Eight tetrachords:

4-1 [0, 1, 2, 3] <321000>: Zhun (屯, Hexagram for Difficulty at the Beginning), Jin ( 晋, Hexagram for Progress);

4-2 [0, 1, 2, 4] <221100>: Mingyi (明夷, Hexagram for Darkening of the Light), Gen (艮, Hexagram for Keeping Still Mountain);

4-7 [0, 1, 4, 5] <201210>: Kan (坎, Hexagram for Abysmal Water), Xiaoguo (小过, Hexagram for Small Preponderance);

4-9 [0, 1, 6, 7] <200022 >: Yí (區, Hexagram for Mouth Corners), Sheng (升, Hexagram for Pushing Upward);

4-10 (12) [0，2，3，5] <122010>: Lin (临, Hexagram for Approach), Meng (蒙, Hexagram for Youthful Folly);

4-20 [0, 1, 5, 8] <101220>: Zhen (震, Hexagram for Arousing Thunder), Guan (观, Hexagram for Contemplation);

4-23 [0, 2, 5, 7] <021030>: Xie (解, Hexagram for Deliverance), Jiăn (寒, Hexagram for Obstruction);

4-28 [0, 3, 6, 9] <004002>: Cui (萃, Hexagram for Gathering Together).

c) Seven hexachords:

6-1 [0, 1, 2, 3, 4, 5] <543210>: Jie (节, Hexagram for Limitation), Lü (旅, Hexagram for Wanderer);

6-8 [0, 2, 3, 4, 5, 7] <343230>: Jiji (既济, Hexagram for After Completion), Weiji (未 济, Hexagram for Before Completion);

6-20 [0, 1, 4, 5, 8, 9] <303630>: Feng (丰, Hexagram for Abundance), Huan (涣, Hexagram for Dispersion);

6-32 [0， 2, 4, 5, 7, 9] <143250>: Guimei (归妹, Hexagram for Marrying Maiden), Jiàn (渐, Hexagram for Development);

6-Z38 [0, 1, 2, 3, 7, 8] \& 6-Z6 [0, 1, 2, 5, 6, 7] <421242>9: Yî (益卦, Hexagram for Increase), Shihe (噬嗑, Hexagram for Biting Through), Heng (恒, Hexagram for Duration), Jing (井, Hexagram for Well);

6-Z42 [0, 1, 2, 3, 6, 9] \& 6-Z13 [0, 1, 3, 4, 6, 7] <324222>: Sui (随, Hexagram for Fowling), Pi (否, Hexagram for Standstill), Tai hexagram (泰, Hexagram for Peace), $\mathrm{Gu}$ (盅, Hexagram for Work on the Decay);

6-Z50 [0, 1, 4, 6, 7, 9] \& 6-Z29 [0, 1, 3, 6, 8, 9] <224232>: Bì (苦, Hexagram for Brace), Sun (损, Hexagram for Decrease), Kùn (困, Hexagram for Oppression), Xian (咸, Hexagram for Influence).

d) Eight octachords:

8-1 [0, 1, 2, 3, 4, 5, 6, 7] <765442>: Xu (需, Hexagram for Waiting), Ding (鼎, Hexagram for Cauldron);

8-7 [0, 1, 2, 3, 4, 5, 8, 9] <645652>: Zhongfu (中孚, Hexagram for Inner Truth), Li ( 离, Hexagram for Clinging Fire);

8-9 [0, 1, 2, 3, 6, 7, 8, 9] <644464>: Wuwang (无妄, Hexagram for Innocence), Daguo (大过, Hexagram for Great Preponderance);

8-10 [0, 2, 3, 4, 5, 6, 7, 9] <566452>: Dui hexagram (兑, Hexagram for Dispersion), Dun (遁, Hexagram for Retreat);

8-17 [0, 1, 3, 4, 5, 6, 8, 9] <546652>: Ge (革, Hexagram for Revolution), Song (讼, Hexagram for Conflict);

8-20 [0, 1, 2, 4, 5, 7, 8, 9] <545662>: Dazhuang (大壮, Hexagram for Great Power), Xun (巽, Hexagram for the Gentle Wind); 
8-23 [0, 1, 2, 3, 5, 7, 8, t] <465472>: Jiaren (家人, Hexagram for the Family), Kui ( 睽, Hexagram for Opposition);

8-28 [0, 1, 3, 4, 6, 7, 9, t] <448444>: Daxu (大畜, Hexagram for Great Taming).

e) Three decachords:

10-1 [0, 1, 2, 3, 4, 5, 6, 7, 8, 9] <988884> Guai (夫, Hexagram for Breakthrough), Gou (循, Hexagram for Coming to Meet);

10-3 [0, 1, 2, 3, 4, 5, 6, 7, 9, t] <889884> Xiaoxu (小畜, Hexagram for Small Taming), Dayou (大有, Hexagram for Great Possession);

10-5 [0, 1, 2, 3, 4, 5, 7, 8, 9, t ] <888894 > Tongren (同人, Hexagram for Fellowship), LV (履, Hexagram for Treating).

f) One dodecachord:

12-1 [0, 1, 2, 3, 4, 5, 6, 7, 8, 9, t, e] <ccccc6> Qián (乾, Hexagram for Creative Heaven).

However, 64 pitch-class sets show another type of category in accordance to Tai Chi list of pitch-class sets, in which the class marks are different, because the dissonance ratio is the means by which the sequence of pitch-class sets arranges in Zhao's set list ${ }^{10}$, rather than interval vector in Allen Forte's theory:

$\left.a^{1}\right)$ Three dyads:

2-1 [0, 5] <0, 0, 0, 0, 1, 0> Qiān (谦, Hexagram for Modesty), Shi (师, Hexagram for Army).

2-3 [0, 3] <001000>: Yu (豫, Hexagram for Enthusiasm), Bı̌ (比卦, Hexagram for Holding Together);

2-6 [0, 1] <100000>: Kūn (坤, Hexagram for the Receptive Earth), Fu (复, Hexagram for Return), Bo (剥, Hexagram for Splitting Apart);

$\left.\mathrm{b}^{1}\right)$ Eight tetrachords:

4-2 [0, 2, 5, 7] <021030>: Xie (解, Hexagram for Deliverance), Jiăn (骞, Hexagram for Obstruction);

4-4 [0, 1, 5, 8] <101220>: Zhen (震, Hexagram for Arousing Thunder), Guan (观, Hexagram for Contemplation);

4-7 [0, 1, 4, 9] <102210>: Lin (临, Hexagram for Approach), Meng (蒙, Hexagram for Youthful Folly);

4-10 [0, 3, 6, 9] <004002>: Cui (萃, Hexagram for Gathering Together);

4-19 [0, 1, 4, 5] <201210>: Kan (坎, Hexagram for Abysmal Water), Xiaoguo (小过, Hexagram for Small Preponderance);

4-20 [0, 2, 3, 5] <122010>: Mingyi (明夷, Hexagram for Darkening of the Light), Gen (艮, Hexagram for Keeping Still Mountain);

4-21 [0, 1, 6, 7] <200022>: Yí (颐, Hexagram for Mouth Corners), Sheng (升, Hexagram for Pushing Upward);

4-28 [0, 1, 2, 3] <321000>: Zhun (屯, Hexagram for Difficulty at the Beginning), Jin (晋, Hexagram for Progress).

$\left.\mathrm{C}^{1}\right)$ Seven hexachords:

6-1 [0, 2, 4, 5, 7, 9] <143250>: Guimei (归妹, Hexagram for Marrying Maiden), Jiàn (渐, Hexagram for Development);

6-3 [0, 1, 4, 5, 8, 9] <303630>: Feng (丰, Hexagram for Abundance), Huan (涣, Hexagram for Dispersion); 
6-8 [0, 1, 4, 6, 7, 9] \& [0, 1, 3, 6, 8, 9] <224232>: Bì (赑, Hexagram for Brace), Sun (损, Hexagram for Decrease), Kùn (困, Hexagram for Oppression), Xian (咸, Hexagram for Influence);

6-24 [0, 2, 3, 4, 5, 7] <343230>: Jiji (既济, Hexagram for After Completion), Weiji (未 济, Hexagram for Before Completion);

6-25 [0, 1, 2, 3, 7, 8] \& [0, 1, 2, 5, 6, 7] <421242>: Yî (益卦, Hexagram for Increase); Shihe (噬嗑, Hexagram for Biting Through), Heng (恒, Hexagram for Duration), Jing (井, Hexagram for Well);

6-26 [0, 1, 3, 4, 6, 7] \& [0, 1, 2, 3, 6, 9] <324222>: Sui (随, Hexagram for Fowling), Tai hexagram (泰, Hexagram for Peace), Gu (盅, Hexagram for Work on the Decay), $P i$ (否, Hexagram for Standstill);

6-35 [0, 1, 2, 3, 4, 5] <543210>: Jie (节, Hexagram for Limitation), Lü (旅, Hexagram for Wanderer).

$\left.\mathrm{d}^{1}\right)$ Eight octachords:

8-2 [0, 1, 2, 3, 5, 7, 8, t] <465472>: Jiaren (家人, Hexagram for the Family), Kui (睽, Hexagram for Opposition);

8-4 [0, 1, 2, 4, 5, 7, 8, 9] <545662>: Dazhuang (大壮, Hexagram for Great Power), Xun (巽, Hexagram for the Gentle Wind);

8-7 [0, 1, 3, 4, 5, 6, 8, 9] <546652>: Ge (革, Hexagram for Revolution), Song (讼, Hexagram for Conflict);

8-10 [0, 1, 3, 4, 6, 7, 9, t] <448444>: Daxu (大畜, Hexagram for Great Taming);

8-19 [0, 1, 2, 3, 4, 5, 8, 9] <645652>: Li (离, Hexagram for Clinging Fire), Zhongfu ( 中孚, Hexagram for Inner Truth);

8-20 [0, 2, 3, 4, 5, 6, 7, 9] <566452>: Dui hexagram (兑, Hexagram for Dispersion), Dun (遁, Hexagram for Retreat);

8-21 [0, 1, 2, 3, 6, 7, 8, 9] <644464>: Wuwang (无妄, Hexagram for Innocence), Daguo (大过, Hexagram for Great Preponderance);

8-28 [0, 1, 2, 3, 4, 5, 6, 7] <765442>: Xu (需, Hexagram for Waiting), Ding (鼎, Hexagram for Cauldron);

$\left.\mathrm{e}^{1}\right)$ Three decachords:

10-6 [0, 1, 2, 3, 4, 5, 6, 7, 8, 9] <988884> Guai (夫, Hexagram for Breakthrough), Gou (循, Hexagram for Coming to Meet);

10-3 [0, 1, 2, 3, 4, 5, 6, 7, 9, t] <889884> Xiaoxu (小畜, Hexagram for Small Taming), Dayou (大有, Hexagram for Great Possession);

10-1 [0, 1, 2, 3, 4, 5, 7, 8, 9, t ] <888894> Tongren (同人, Hexagram for Fellowship), LV (履, Hexagram for Treating).

f) One dodecachord:

12-1 [0, 1, 2, 3, 4, 5, 6, 7, 8, 9, t, e] <ccccc6> Qián (乾, Hexagram for Creative Heaven).

Each hexagram is associated with another hexagram that is the opposite by a diameter in a complementary relationship, which is called duigua (对卦, a pair of opposite hexagrams). Therefore, the combination of this type of dyad comprises a twelve-tone, such as Zhen and Xun (Ex. 10). According to this analogy, 32 twelve-tone series are generated, reflecting the complementary relationship of Serialism, in which one set is the complement of another. 


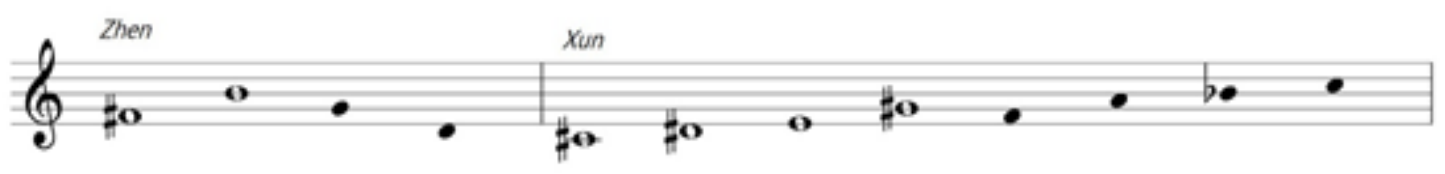

Ex. 10: The complement sets of Zhen and Xun.

In accordance to the theory of yin and yang, in the span of the second interval (minor second, major second and augmented second), in which the relatively smaller interval is yin and the relatively larger interval is yang, the quantity of modes is expanded to 189 (64×3-3), in accordance with the three types of arrangements that include the following: the first pattern, in which a minor second represents yin and a major second represents yang; the second pattern, in which a major second represents yin and an augmented second represents yang; and the third pattern, in which a minor second represents yin and an augmented second represents yang. The permutation of modes is similar to the pitch classes of the 64 hexagrams, which arrange the scale according to the order of the yin-yang interval relationship, in reference to the hexagram image. However, the sequence to array the interval corresponds to both the broken and the unbroken lines of each hexagram from bottom to top. Ex. 11 shows three modes of the Kan hexagram 堆 based on the different yinyang patterns.

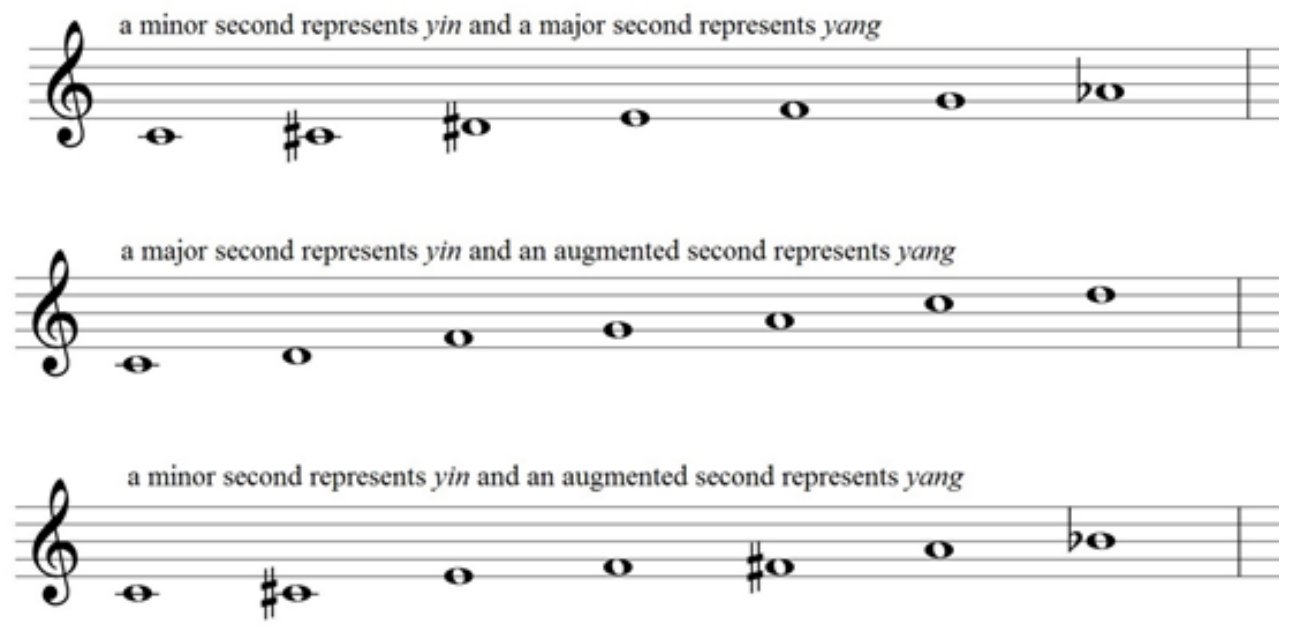

Ex. 11: Three modes of the Kan hexagram.

The same approach is employed in building the yin-yang chord, except for the different presets of the yin-yang interval relationship. Three pairs of third intervals construct the $189(64 \times 3-3)$ chords, the relations of which are a minor third (yin) to a major third (yang), a major third (yin) to an augmented third (yang) and a minor third (yin) to an augmented third (yang). The three chords of the Kan hexagram 盖 are depicted in Ex. 12 as an example:

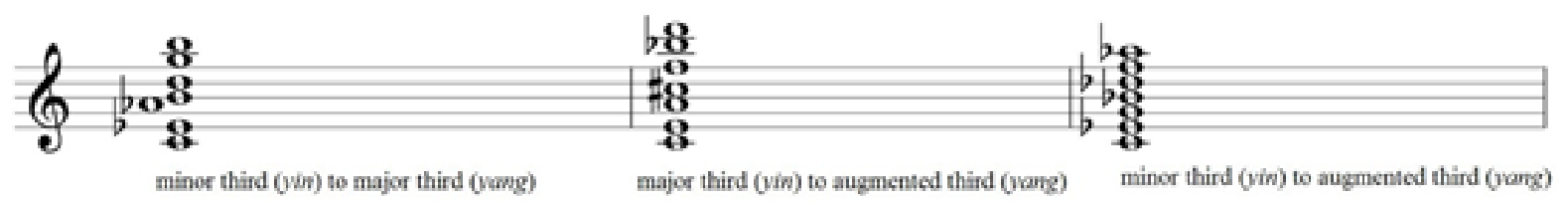

Ex. 12: Three chords of the Kan hexagram 


\section{Chung Yiu Kwong's I Ching Compositional System}

In 1995, Chung Yiu Kwong invented the I Ching Compositional System (hereinafter ICCS) and interpreted it in his doctoral thesis, entitled "The I Ching Compositional System: the Symbolism, Structures, and Orderly Sequence of the Sixty-four Hexagrams as Compositional Determinants." During a recent interview with Chung, the composer explained that it was Zhao Xiaosheng's TCCS that inspired him to create ICCS, although there are many differences between them, especially in their approaches (CHUNG, 2017). The hierarchical structure of ICCS is based on Schenker's theory ${ }^{11}$, which comprises the fundamental series (or ursatz) of background, middle ground and foreground.

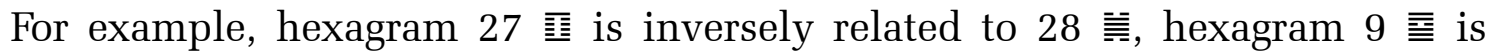
retrograde related to 10 豆, hexagram 25 豆 is interchangeably related to 34 豆, hexagrams 5 琶 and 6 豆 possess the relations of retrograde and interchange, and hexagrams 63 垃 and 64 至 contain the relations of inversion, retrograde and interchange. According to the binary of the I Ching that a broken line is 0 and an unbroken line is 1 (GUO, 2013; RYAN, 1996), the vector of the hexagram can be concluded by the broken and unbroken lines of the hexagram from bottom to top. Therefore, the inverse relation between hexagrams 27 and 28 represents I (100001) [27] = (011110) [28], and by analogy, the retrograde-related hexagrams 9 and 10 represent $R$ (111011) [9] = (110111) [10].

Based on the symbolism that the twelve hexagrams $(11,34,43,1,44,33,12$, $20,23,2,24,19)$ correspond to the twelve months of the year, also called the twelve bi hexagrams (十二辟卦) ${ }^{12}$, a series of twelve pitches is concluded, namely, huangzhong (黄 钟, tonic), dalv (大吕, semitone), taicu (太簇, major second), jiazhong (夹钟, minor third), guxian (姑冼, major third), zhonglv (中吕, perfect fourth), ruibin (穀宾, tri-tone), linzhong (林钟, perfect fifth), yize (夷则, minor sixth), nanlv (南吕, major sixth), wuyi (无射, minor seventh), and yingzhong (应钟, major seventh) (XU, 2016). Compared to the twelve ancient Chinese pitches, Chung's pitches are two mirrored hexachords from the interior to two sides, reflecting the waxing and waning of yin and yang. In addition, the sequence of pitches is preset under the premise of hypothesizing that the Qian (乾, Hexagram for the Creative Heaven) is 0. Tab. 3 shows the correlations of hexagrams with the twelve months and twelve ancient Chinese pitches, along with the pitches and sequence that Chung presents. A novel presumption that yin and yang are transpositions of the sixth-interval relation is offered by Chung. For example, to hypothesize that the pitch-class $x(0-11)$ is a yang note, the pitch-class $\mathrm{x}+6$ will have to be a yin note, and therefore, the yang note $\mathrm{x}$ and the yin note $\mathrm{x}+6$ are T6-related ${ }^{13}$.

\begin{tabular}{|c|c|c|c|c|c|c|c|c|c|c|c|c|}
\hline Hexagram & 11 & 34 & 43 & 1 & 44 & 33 & 12 & 20 & 23 & 2 & 24 & 19 \\
\hline Month & Jan. & Feb. & Mar. & Apr. & May & June & July & Aug. & Sep. & Oct. & Nov. & Dec \\
\hline Symbol & $\underline{\underline{\underline{\mu}}}$ & 쏠 & 늘 & 를 & 豆 & 豆 & 豆 & 五 & III & III & $\Perp$ & $\underline{\underline{\Perp}}$ \\
\hline $\begin{array}{l}\text { Twelve } \\
\text { pitches }\end{array}$ & taicu & jiazhong & guxrian & zhongh $v$ & nuibin & linzhong & yize & nanlv & พuyi & yingzhang & huangzhong & dah \\
\hline $\begin{array}{l}\text { Chung's } \\
\text { pitches }\end{array}$ & G & $\mathrm{G} \#$ & A & $\mathrm{A} \#$ & B & C & $\mathrm{C} \#$ & D & $\mathrm{D} \#$ & E & F & $\mathrm{F} \#$ \\
\hline $\begin{array}{l}\text { Chung's } \\
\text { sequences }\end{array}$ & 9 & $t$ & $\mathrm{e}$ & 0 & 1 & 2 & 3 & 4 & 5 & 6 & 7 & 8 \\
\hline
\end{tabular}

Tab. 3: The correlations of hexagrams with the twelve months, twelve ancient Chinese pitches, Chung's pitches and sequences 
Rooted in the T6-relationship between yin and yang, the four fundamental series (marked by FS) that form the basis of ICCS are concluded, namely, FS1: [01e2t3948576], FS2: [07e8t9342516], FS3: [0158t3942e76] and FS4: [0752t9348e16], along with the composer's rules, for example, that the distance between the first and the last notes is a tri-tone, that two hexachords (H1 and H2) retrograde equivalently and transform in the same direction (forward or backward), that all-interval classes, except for interval class 6, are included in the series, and that two hexagrams are combinations under the relations of transposition, inversion, retrograde or retrograde-inversion. Each fundamental series can derive 12 retrograde-related sets and 12 retrograde-inversion sets. Therefore, $96(4 \times 12 \times 2)$ series are generated, which are marked by FSPn or FSIn ( $P$ stands for the relation of retrograde, $I$ stands for the retrograde-inversion, and $n$ denotes the integer of transposition ranging from 1 to 4). For example, fundamental series [0158t3942e76] is noted by FS3P0, whereas [102e3t495867] denotes FS1I1.

The transformation between yin and yang highlights the logical structure of the fundamental series, in which the pitches correspond to the twelve-hexagram symbols that reflect an inversionally symmetrical pattern through the arrangement of hexagrams from pure yang (Qian hexagram) to pure yin (Kun hexagram), which is the order of Shao Yong's sequence (CHUNG, 1995). According to the waxing and waning progress of hexagram symbols, the midpoint in the fundamental series usually shows attributes of both yin and yang. Therefore, Chung denotes the sixth and seventh notes as notes of yin-yang interaction, the second note as a note of activation, the eleventh note as a note of stabilization, the third note as a note of development, the tenth note as a reversion, the fourth and ninth notes as notes of transposition and the fifth and eighth notes as notes of yin-yang displacement.

With regard to understanding Tai Chi, Chung depicts the two-part Tai Chi diagram through two fundamental series that are RI-related. Taking FS4IO as an example, the Tai Chi series forms a combination of series P0: [057t239841e6] and RI0: [61e8439t2570].

By calculating the four numbers extracted from the second, third, fifth and tenth notes of the fundamental series of either P0 or I0 forms, the results are limited to the tetrachords 4-Z29 [0, 1, 3, 7] and 4- Z15 [0, 1, 4, 6]. Therefore, the sets [0, 1, 3, 7] and [0, 1, $4,6]$ become the subsets that constitute the background of ICCS.

Similar to Zhao, the progress of fission from Tai Chi to the 64 hexagrams is also utilized in ICCS as the theory's foundation. However, the operation between them is completely different. Chung establishes up four layers to decode the evolutionary procedure in which Tai Chi generates two poles, the two poles generate four images, and the four images generate eight trigrams, which then produce 64 hexagrams. In terms of the two poles, Chung presents $\mathrm{C}$ and $\mathrm{F} \#$ to represent yang and yin, respectively, which are T6 related. Based on the two poles, two pitches of yin-yang interaction, Eb and A in $\mathrm{RI}_{0}$ relation, are added to construct four images. In the third layer, Chung adds four dyads ( $\mathrm{C \#}$ and $\mathrm{G}, \mathrm{Bb}$ and $\mathrm{E}, \mathrm{B}$ and $\mathrm{F}$, and $\mathrm{G \#}$ and $\mathrm{D}$ ) to represent eight trigrams, which are all -interval tetrachords with same interval vectors. In the fourth layer, the Tai Chi series plays the role of the urlinie composition, in which each pitch of the Tai Chi series is bracketed by the all-interval tetrachords of the third layer that add the second and eleventh notes as common tones. The common tones are also called the notes of vitality by Chung because the second (note of activation) and eleventh (note of stabilization) notes can be integrated with the first and sixth notes, seventh and twelfth notes, third and fourth notes and ninth and tenth notes to form the all-interval tetrachords that have the same prime form. For example, when hypothesizing the notes of vitality by combining the first and sixth notes, a tetrachord embedded in FS1P0: [01e2t3948576] emerges as <0, 1, 3, 7>, the prime form of 
which is $[0,1,3,7]$. Extracting the notes of vitality and the seventh and twelfth notes, the tetrachord is denoted as PART ${ }_{(1,6, \mathrm{t}, \mathrm{e})}(F S 1 P 0:[01 \mathrm{E} 2 \mathrm{~T} 3948576])=<1,9,7,6>$, with the set class (0137). According to the symmetrical pattern of the fundamental series, if the dyad $F$, B becomes the second and eleventh notes (or notes of vitality), the dyad C\#, G are the third and tenth notes and vice versa. For example, if the FS4PO series is [0752t9348e16], and the FS4IO series is [057t239841e6], based on the premise of $\mathrm{C}=0$, the dyad C\#, $\mathrm{G}$ becomes the notes of vitality, and F and B are the third and tenth notes in the FS4PO series. Similarly, the dyad F, B becomes the notes of vitality, and C\# and G are the third and tenth notes in the FS4IO series. In summary, the 64 hexagrams or myriad things are presented in the following form, based on the premise of the FS1P0 series (Ex. 13):

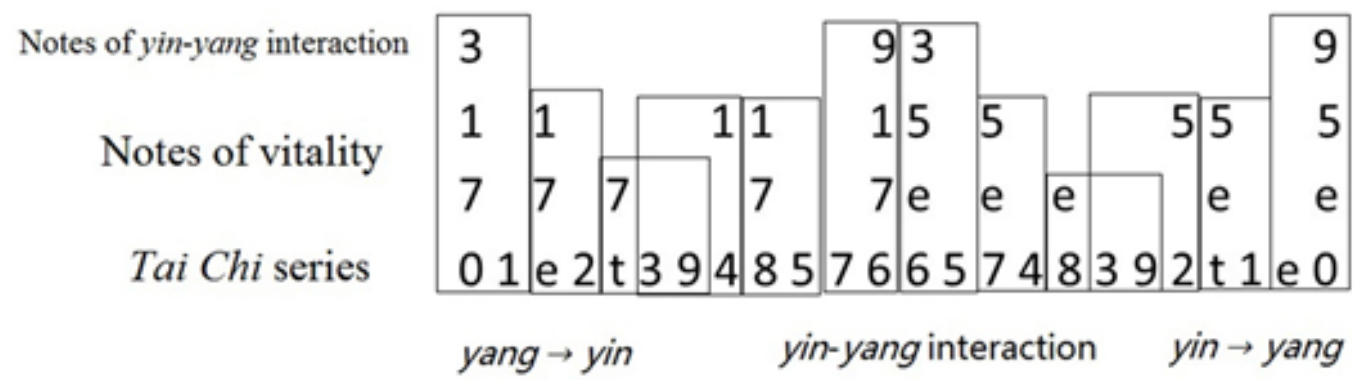

Ex. 13. The structures of the 64 hexagrams or myriad things.

As seen in Ex. 13, the music reflects a process of yang-yin-yang and produces twelve tetrachords that possess the same prime form [0, 1, 3, 7]. In addition to the above example, the structure of the background can be established with other FS series, such as FS1P0, FS3P0, FS4P0, FS1IO, FS2IO, FS3I0 and FS4IO. The prime form of the tetrachords becomes [0, 1, 4, 6] by adopting FS2P0, FS4P0, FS2IO and FS4IO.

Based on the Schenker's theory, the middleground resembles tree branches, which show a harmonic skeleton (ZHOU, 1987). In ICCS, the middleground is composed of the structural notes, predetermined by the hexagram symbols and yin-yang series. The yin-yang series includes two hexachords: $\mathrm{H} 1$, consisting of $\mathrm{C}, \mathrm{A}, \mathrm{G}, \mathrm{D}, \mathrm{Bb}$ and $\mathrm{B}$, and $\mathrm{H} 2$, consisting of F, E, G\#, C\#, D\#, and F\#, where the dyads of C- F\#, A- D\#, G- C\#, D- G\#, Bb- E and B$\mathrm{F}$ are T6-related and symmetrical. Whereas the second note of each dyad is the counterpart of the first note in $\mathrm{H} 2$ (Tab. 4).

\begin{tabular}{|c|c|c|}
\hline H1 & & H2 \\
\hline $\mathrm{C}$ & \multirow{6}{*}{ T6-relation } & $\mathrm{F}$ \\
\hline $\mathrm{A}$ & & E \\
\hline G & & $\mathrm{G} \#$ \\
\hline $\mathrm{D}$ & & C\# \\
\hline $\mathrm{Bb}$ & & D\# \\
\hline B & & F\# \\
\hline
\end{tabular}

Tab. 4: The T-relations between $\mathrm{H} 1$ and $\mathrm{H} 2$.

Integrating the hexagram symbols and yin-yang series, the middleground structural notes are obtained by selecting proper notes that comprise the pitches in $\mathrm{H} 1$ to correspond to the unbroken lines of a hexagram symbol and the counterparts of 
pitches in $\mathrm{H} 2$ that correspond to the broken lines. For example, for the hexagram symbol 豆, from bottom to top, F corresponds to the first line (broken line), A to the second line, $\mathrm{G}$ to the third line, $\mathrm{D}$ to the fourth line, $\mathrm{Bb}$ to the fifth line and $\mathrm{F} \#$ to the sixth line.

Most of the 64 hexagrams are retrograde, inversion, interchange or mix related, as mentioned in the above context, and the structural notes are derived from the relation between two hexagrams. For example, hexagrams 3 and 50 are I-related, the series of hexagram 3 is [142653], and the series of hexagram 50 is [635124] because of the I-relation of the sequence (Tab. 5). Hexagrams 3 and 49 are RI-related, the series of hexagram 49 is [421536], and the interchange-related series is [653142], which belongs to hexagram 40 . The combination of two or more related hexagrams creates multi-relations, from which one is selected.

\begin{tabular}{|c|c|}
\hline Prime sequence & I-related sequence \\
\hline 1 & 6 \\
\hline 2 & 5 \\
\hline 3 & 4 \\
\hline 4 & 3 \\
\hline 5 & 2 \\
\hline 6 & 1 \\
\hline
\end{tabular}

Tab. 5: I-relations of sequences.

The connection of the background's Tai Chi series with the middleground structure is based on the premise of the linear ordering of the yin-yang tetrachord, following the original ordering in the Tai Chi series. Taking the first tetrachord in Ex. 13 as an example, with reference to the ordering of the Tai Chi series, the tetrachord is C, F, Eb and B. When allocating the pitches of this tetrachord, four patterns of hexachords are produced: $(0,9$, e, t, 2, 7), (5, 4, 6, 3, 1, 8), $(0,8,3,5, \mathrm{t}, 1)$ and $(1,4, \mathrm{e}, 9,8,6)$. Among them, the first two patterns are affiliated with the pitch-class set $6-8[0,2,3,4,5,7]$, whereas the last two patterns are 6-32 [0, 2, 4, 5, 7, 9]. These four-pattern series construct the linear structure of the middle ground and any pitch of the tetrachords can be linked by various decorations, such as timbre, rhythm, dynamics and register.

In ICCS, the foreground interprets the judgments, commentaries and orderly sequences of the 64 hexagrams. Along with the order of yin-yang transformation interpreted by many sinologists, the form of ICCS resembles to the Western sonata (CHUNG, 1995), which consists of exposition, development, recapitulation and coda (Tab. 6).

\begin{tabular}{|c|c|c|c|c|c|c|c|c|c|c|}
\hline \multirow{2}{*}{$\begin{array}{l}\text { Section } \\
\text { Hexagram }\end{array}$} & \multicolumn{3}{|c|}{ Exposition } & \multicolumn{3}{|c|}{ Development } & \multicolumn{2}{|c|}{ Recapitulation } & \multicolumn{2}{|c|}{ coda } \\
\hline & $1-2$ & $3-11$ & $12-24$ & $\begin{array}{l}25- \\
38\end{array}$ & $\begin{array}{l}39 . \\
44\end{array}$ & $45-52$ & $53-59$ & $60-62$ & 63 & 64 \\
\hline & $\begin{array}{l}\mathrm{A}, \\
\mathrm{B}\end{array}$ & $\begin{array}{l}\text { lst } \\
\text { interaction } \\
\text { of A and B }\end{array}$ & $\begin{array}{l}\text { 2nd } \\
\text { interaction } \\
\text { of A and B }\end{array}$ & C & D & $\begin{array}{l}\text { Interaction } \\
\text { of A, B, C, } \\
\text { and D }\end{array}$ & $\begin{array}{l}\text { lst } \\
\text { restatement } \\
\text { of A, B, C, } \\
\text { and D }\end{array}$ & $\begin{array}{l}\text { 2nd } \\
\text { restatement } \\
\text { of A, B, C, } \\
\text { and D }\end{array}$ & $\begin{array}{l}\text { A, } \\
\text { B }\end{array}$ & $\begin{array}{l}\text { C, } \\
\text { D }\end{array}$ \\
\hline
\end{tabular}

Tab. 6: The structure of foreground. 
The combination of guaci (卦辞, explanation of hexagrams) and musical discourse brackets the construction of the foreground. Examples of this construction include the hexagrams Qian and Kun, which symbolizes heaven and Earth in 64 hexagrams. The following passage describes the hexagrams Qian and Kun: "Qian, the origin of all beings; Kun, the nature of all beings growing; only with the combination of Qian and Kun, can life begin..." (JIN, 1937, p. 120, translation by the authors).

Therefore, element A shows the creative attribution of yang, while the receptive element B represents yin.

Another example is hexagram 45, entitled Cui (萃, Hexagram for Gathering Together): "Cui means assemble, to obey to make others (emperor) pleasing, but with staunch faith in the heart; therefore, it indicates gathering" (JIN, 1937, p. 307, translation by the authors).

Therefore, as the music enters the Cui hexagram, the omen of integration among all the musical materials (elements A, B, C, and D) appears.

\section{Discussion of the Transcoded 64 Hexagrams}

In this article, compositional technique based on I Ching evolved in the early 1960s, 1980s, and 1995 shows a development of thoughts in the 64 hexagrams transcoded into musical pitches and concepts. Although the twelve-tone temperament is the constructed basis of the three compositional systems, which are VM, TCCS and ICCS, the segmentations display their differences. In VM, utilizing trichotomy, a twelve-tone is divided into three parts to represent Heaven, Humans and the Earth that correspond with three lines of the eight trigrams. In contrast to Chou's VM, a dichotomy between the yin and yang is applied to divide the twelve-tone into two symmetrical parts, synthesized Tai Chi chord in Zhao's perspective, depicts the pattern of the two-part Tai Chi diagram. In Chung's system, the dichotomy reflects the two hexachords that are in retrograde-equivalence.

In the original conception in the I Ching, yin-yang becomes the foundation for constructing pitches, scales, modes, arrangements and other concepts in three compositional systems. In Chou's conception, the structure of a major second plus a major second symbolizes yinyao (broken line), and a minor third plus a minor second symbolizes yangyao (unbroken line). By arranging the presentations of yinyao and yangyao, eight modes corresponding to the eight trigrams emerge. In the aforementioned context, Zhao uses the three patterns of second intervals representing yin and yang, to construct modes and three patterns of third intervals to construct chords, extending the range of permutations on modes and chords (189 modes and 189 chords). In Chung's theory, yin and yang are T6related; in other words, yin = yang +6 .

As the philosophical concept of I Ching, yin and yang can be mutually transformed, as narrated below:

The sun goes, and the moon comes; the moon goes, and the sun comes; the sun and moon thus take the place of each other, and their shining is the result. The cold goes, and the heat comes; the heat goes, and the cold comes; it is by this mutual succession of the cold and heat that the year is completed (LEGGE, 1963, p. 389).

Chou, Zhao and Chung all consider the application of I Ching and transcoded into 64 hexagrams as composition method. The transformation between yin and yang in VM reflects the orientations. For example, the yin-attribute of C-E in the ascending scale is altered as an attribute of yang in the descending scale, whereas the yang-property of G\#-C in the ascending scale transforms into the yin attribute of Ab-E in the descending scale. In 
Zhao's system, especially in his piano solo composition, also entitled Tai Chi, the music begins from yin (Kun), climaxes to yang (Qián) and ends with yin (Kun) again, embodying a cyclical movement. Moreover, Zhao's calculation of the 64 sets of pitch classes embodies the rule of interaction between yin and yang, in which one is waning and the other is waxing. Chung's assumption breaks through the limitations of yin and yang because it also assumes that the sixth and seventh notes are notes of yin-yang interaction in the medium of yin and yang, with an emphasis on the converted progress from yang to yin or yin to yang. In addition, Chung designed another path in the fourth layer of the background structure that shows a yang-yin-yang process.

The composers' notations are also different. Chou continues to use conventional notation, whereas Zhao and Chung apply black-head and white-head notes to distinguish between yin and yang. Nevertheless, the white-head notes in Zhao's notation indicate yang and vice versa. In Chung's theory, the black-head notes refer to notes of vitality, whereas the white notes represent notes of yin-yang interaction and Tai Chi series, and the four of them construct a yin-yang tetrachord.

The hexagram symbols are the basis of construction among the three compositional systems, but their purposes and methods vary in the three composers: an establishment of modes in Chou, pitch-class sets, modes and chords in Zhao, and Chung utilizes them to create fundamental series, structural notes of the middleground, and orderly sequences.

The superimposition of two of the eight trigrams generates one of the 64 hexagrams, which is also called chonggua (重卦, superimposition of trigrams). According to this principle, Chou applies the synthesis of two trigrams on the premise that two trigrams are displayed on reverse scales apart from a minor second. The 64 sets of pitch classes are the means by which 64 hexagrams are reflected in Zhao's TCCS; he obtained the pitch classes symbolizing 64 hexagrams by removing the yin notes from the Tai Chi chord and reserving the yang notes, according to the alternation of the broken and unbroken lines of each hexagram. In addition, Zhao uses the duigua method to combine the dyads located at opposite positions in the Tai Chi diagram to form a twelve-tone. Chung's composition reflects the structure of the 64 hexagrams. He stipulates that all the compositions in ICCS have 64 sections, although the number of movements varies (CHUNG, 1995, p. 52). Additionally, the 64 hexagrams transcend the definition of the hexagram itself on behalf of myriad things when constructing the fourth layer of the background. Furthermore, the commentaries of the 64 hexagrams are applied in Chung's system to construct the foreground which however, are absent in Chou's and Zhao's work.

Composition training in the United States and exposure to the contemporary musical environment are similarities among three composers, which led to influences in Serialism as the fundamental individual compositional theory. However, because of their different ages and periods of education, their tonality tendencies are distinct. The most tonal tendency should be VM, in which the eight modes named after the properties of the eight trigrams show the centrality of every mode. Moreover, Chou utilizes the ascending and descending scales to describe the mode, which is similar to the major and minor modes that emphasize the centrality of tonality. Drawing on the pitch-class theory of Allen Forte, Zhao's TCCS entered the world of pitch class when he presented 64 groups of pitch classes corresponding to the 64 hexagrams to create a novel sound circumstance. However, the centrality of tonality has been changed from modes to hexagrams. Zhao's theory can be viewed as either tonal or atonal music (ZHAO, 2006). Based on the Schenker's theory, Chung established a completely atonal compositional system in which the methods of transposition, retrograde, inversion and methods are applied to establish serials. Coincidentally, as seen 
from the alternation related to tonality from tonal to atonal in the three composers' systems, a clear procedure is shown, that is, the Chinese composers' association of Serialism with the ancient Chinese philosophy of the I Ching.

Different understandings of the I Ching are reflected in Chou, Zhao and Chung's compositional systems. For instance, the eight trigrams conduct the modes in Chou's VM, whereas the 64 hexagrams lead Zhao's TCCS. Compared to Chou and Zhao, a more comprehensive consideration of the I Ching is applied in Chung's ICCS, which includes the thoughts of both hexagrams and corresponding judgments and commentaries in a threedimensional space that consists of background, middleground and foreground. Because Serialism is the Western fundamental theory of all three compositional systems, the mathematical ideal of the I Ching is one of the similarities of their creations in formulating pitch classes, modes and series. In addition, other thoughts regarding the I Ching, such as symmetry, dualism, the philosophy of life and the universe, are reflected in the three composers' theories.

Although three composers articulated Serialism in the same breath, their manners are of distinct differences. Comparing Chou's borrow of the Western compositional technique and Chung's ICCS shows an unquestionable application of Serialism. It was Zhao who made a difference to Western Serialism. For example, in TCCS, the sequence of pitch class is omitted and the interval vectors are reserved; two pitch classes can be separated to utilize; it is not necessary that all pitch classes must appear in one time; pitch classes can be repeated; and tonal is accepted (WANG, 2004). In addition, Zhao invented his own pitch-class theory that emphasizes the more concerns about soundscape and interior tension among the intervals than Allen Forte's.

In general, Tab. 7 displays the contrasts among the three compositional systems. 


\begin{tabular}{|c|c|c|c|c|c|}
\hline & & VM & \multicolumn{2}{|c|}{ TCCS } & ICCS \\
\hline \multicolumn{2}{|c|}{ Year of creation } & Early $1960 \mathrm{~s}$ & \multicolumn{2}{|c|}{$1980 \mathrm{~s}$} & 1995 \\
\hline \multicolumn{2}{|c|}{ Duration in US } & 1946-present & \multicolumn{2}{|c|}{$1981-1984$} & $\begin{array}{c}\text { End of the } 1970 \mathrm{~s} \\
1986-1995\end{array}$ \\
\hline \multicolumn{2}{|c|}{ Segmentation } & Trichotomy & \multicolumn{2}{|c|}{ Dichotomy } & Dichotomy \\
\hline \multicolumn{2}{|c|}{$\begin{array}{l}\text { Vin-yang } \\
\text { presentation }\end{array}$} & $\begin{array}{l}\text { Minor 3rd +minor 2nd } \\
=\text { yang } \\
\text { Major } 2 \mathrm{nd}+\text { major } 2 \mathrm{nd} \\
=\text { yin }\end{array}$ & $\begin{array}{l}\text { Mode: } \\
\text { 1. Minor 2nd } \\
\text { (yin) to major 2nd } \\
\text { (yang); } \\
\text { 2. Major 2nd } \\
\text { (yin) to } \\
\text { augmented 2nd } \\
\text { (yang); } \\
\text { 3. Minor 2nd } \\
\text { (yin) to } \\
\text { augmented 2nd } \\
\text { (yang) }\end{array}$ & $\begin{array}{l}\text { Chord: } \\
\text { 1. Minor 3rd (yin) } \\
\text { to major 3rd } \\
\text { (yang); } \\
\text { 2. Major 3rd (yin) } \\
\text { to augmented } \\
\text { 3rd (yang); } \\
\text { 3. Minor 3rd (yin) } \\
\text { to augmented 3rd } \\
\text { (yang) }\end{array}$ & $\operatorname{Yin}=$ yang +6 \\
\hline \multicolumn{2}{|c|}{$\begin{array}{l}\text { Yin-yang } \\
\text { transformation }\end{array}$} & $\begin{array}{l}\text { Ascending and } \\
\text { descending scales }\end{array}$ & \multicolumn{2}{|c|}{ Yin-yang-yin } & Yang-yin-yang \\
\hline \multicolumn{2}{|c|}{ Yin-yang notation } & None & \multicolumn{2}{|c|}{$\begin{array}{l}\text { White- head notes }=\text { yang } \\
\text { Black- head notes }=\text { yin }\end{array}$} & $\begin{array}{l}\text { Black- head notes = notes } \\
\text { of vitality = yin } \\
\text { White- head notes = Tai } \\
\text { Chi series or notes of yin- } \\
\text { yang interaction = yang }\end{array}$ \\
\hline \multicolumn{2}{|c|}{ Symbol of hexagram } & Modes & \multicolumn{2}{|l|}{$\begin{array}{l}\text { Modes } \\
\text { Pitch-class sets } \\
\text { Chords }\end{array}$} & $\begin{array}{l}\text { Structural notes of the } \\
\text { middleground } \\
\text { Fundamental series } \\
\text { Orderly sequences }\end{array}$ \\
\hline \multicolumn{2}{|c|}{64 hexagrams } & $\begin{array}{l}\text { Chonggua in reserve- } \\
\text { direction scales }\end{array}$ & \multicolumn{2}{|c|}{$\begin{array}{l}64 \text { sets of pitch classes } \\
\text { Duigua in combinations of dyads }\end{array}$} & $\begin{array}{l}64 \text { sections } \\
64 \text { hexagrams that also } \\
\text { indicate myriad things } \\
\text { The judgments and } \\
\text { commentaries of the } 64 \\
\text { hexagrams }\end{array}$ \\
\hline \multirow{2}{*}{$\begin{array}{l}\text { Basic } \\
\text { theory }\end{array}$} & Western & $\begin{array}{l}\text { Borrowing Serialism } \\
\text { (tonal }^{16} \text { ) }\end{array}$ & \multicolumn{2}{|c|}{$\begin{array}{l}\text { Changing Serialism } \\
\text { (either tonal or atonal }{ }^{17} \text { ) }\end{array}$} & $\begin{array}{l}\text { Applying Serialism } \\
\text { (atonal) }\end{array}$ \\
\hline & I Ching & $\begin{array}{l}\text { Eight trigrams } \\
\text { Mathematical ideal } \\
\text { symmetry }\end{array}$ & \multicolumn{2}{|c|}{$\begin{array}{l}64 \text { hexagrams } \\
\text { Symmetry } \\
\text { Dualism } \\
\text { Thoughts of life and the universe }\end{array}$} & $\begin{array}{l}64 \text { hexagrams and } \\
\text { corresponding judgements } \\
\text { and commentaries } \\
\text { Symmetry } \\
\text { Sequence } \\
\text { Thoughts of the universe }\end{array}$ \\
\hline
\end{tabular}

Tab. 7: The contrasts among Chou, Zhao and Chung's compositional systems.

\section{Conclusion}

The compositional systems created by Chou, Zhao and Chung possess relationships of the same strain, although they have different standpoints and techniques to display their thoughts about the I Ching. In Chou's VM, the idealism of the I Ching in music creates the 
possibility of utilizing the ideas of ancient philosophy to create a novel musical formation. Although Chung acknowledged that Chou's VM is not a real compositional system (CHUNG, 2017), it is hard to say that two later generation composers was not inspired by VM, especially Zhao Xiaosheng. Along with Chou's attempts, the presentations of yin and yang in Zhao's system were improved by increasing the arrangement of modes and narrowing the distance, which is one second apart. In addition, the 64 hexagrams can be symbolized by specific pitch classes in Zhao's compositional system, revealing the discipline of continual movement among the hexagrams and their transmission by sound. Chung absorbed the essences of Zhao's system to create an innovative compositional system, which contains the ideals of presets, calculation, and innovational symmetry from the Schenker's theory. As the commentaries and judgments of hexagrams inject new vitality into the examination of the I Ching in musical composition, the orderly concepts of the $I$ Ching offer the prerequisite for the construction of series. Although the application of the I Ching in the three compositional systems is increasingly more complex and abundant, the characteristics of change, circulation, yin-yang dualism and symbols are shared, and calculus is the common method among them.

Nevertheless, based on the significance of Chinese new music exploration, the depth and breadth of culture in TCCS is beyond the other two, even though the I Ching is the fundamental of three composition systems. This is due to Zhao is always in the quest of identity in the course of Chinese new wave music along with other third generation composers ("New Wave" composers) in mainland China. Perhaps different cultural and aesthetic background may lead to varied expression in their works, as Bruner (1986) maintained that expression was the cultural result defined from a person's cognition, consciousness, feeling to the personal experience. Zhao experienced some drastic social changes, including the founding of People's Republic of China, Cultural Revolution and Reforming and Openingup in succession. Especially during the period of Cultural Revolution, the composers were required to "send down (下放)" to undergo the physical labors' hardships in the rustication movement (上山下乡运动). In this period, the composers had opportunities to contact with the folk music when they labored with farmers, fishermen, or herdsmen, which became the materials applied in their later compositions (WANG, 1988; ZHOU, 1993). Thereby, Zhao's TCCS was produced under the requirement of fusing national culture and idealism into compositions and seeking an individuality between the traditional music and Western compositional techniques in 20th century, which was the consensus among the composers during the 1980s (LANG, 1986). The TCCS, a result of applying complete essence of I Ching, was thorough in a sense that it is not only an adaptation but of a novel one.

Conversely, Chou experienced the social turmoil during the Second Sino-Japanese War when he was a teenager and his identity as Chinese-American led to his continual experiments of music between the West and East (CHANG, 2001). In addition, he has to consider the aesthetics of Western listeners and thereby, cultivated by Western aesthetics. Accordingly, a type of cross-cultural influence occurred in his VM, more or less with some collisions, in other word, his VM does not display a profound "Chineseness." Similarly, Chung, a Hong Kong born Taiwanese composer applies Chinese culture to twelve-tone serialism but is lacking of a Chinese identity because his works resemble to that of modern Western composers.

As a summary, Zhao's TCCS sees a breakthrough among Chinese contemporary composers who attempt to change Western theory and compositional techniques in order to adapt to a stronger Chinese identity. Zhao direct "borrowing" or "transplant" to a minimum in his work. The significance of TCCS is therefore an important composition in the history 


\section{of Chinese composers where Zhao's creativity is exemplary in the identity and stylistic formation of China new music.}

\section{Notes}

$1 \mathrm{Fu} \mathrm{Xi,} \mathrm{considered} \mathrm{the} \mathrm{originator} \mathrm{of} \mathrm{the} \mathrm{I} \mathrm{Ching,} \mathrm{is} \mathrm{a} \mathrm{cultural} \mathrm{hero} \mathrm{in} \mathrm{Chinese} \mathrm{legend} \mathrm{and} \mathrm{mythology.}$

2 Shiyi (十翼, Ten Wings ), also called Yizhuan (易传, Explanation of I Ching), contains Tuanzhuanshang (彖传上, Commentary of Judgment, 1st), Tuanzhuanxia (彖传下, Commentary of Judgment, 2nd), Xiangshangzhuan (象上传, Overall Image), Xiangxiazhuan (象下传, Little Image), Xicizhuanshang (系辞传上, Commentary on the Appended Phrases, 1st), Xicizhuanxia (系辞传下, Commentary on the Appended Phrases, 2nd), Wenyanzhuan (文言传, Commentary of the Words), Xuguazhuan (序卦传, Sequence of the Hexagrams), Shuoguahuan (说卦传, Explanation of Trigrams), and Zaguazhuan (杂卦传, Assorted or Miscellaneous Hexagrams).

3 In Chen's (2008) dissertation, Taiwanese composers were categorized by four generations. The first generation composers studied in Japan after the First Sino-Japanese War and trained in China mainland and retreated in Taiwan following the nationalist government when the War of Liberation ended. The second generation composers studied in either Europe or America, imitating the compositional features from Debussy to Schonberg. The third generation composers indicated those who were educated by the second generation and continued to study in Europe and America, the genres such as avant-garde, serialism, electronic and computer music, and concerted music were reflected in their compositions. The fourth generation composers born after 1950 and also study abroad, experiment with music that has modern Taiwanese elements.

4 The initiation of Tai Chi Composition System is dated back to the piano concerto The God of Hope in 1985, the representative of joint forces theory. In 1986, Zhao finished the orchestra suite Four Chapters of Simple Music as the result of pitch-class theory. Finally, the piano solo Tai Chi landed a remarkable completion of the Tai Chi theory in 1987. The three theories of joint forces, pitch-class and Tai Chi firstly appeared in December, 1987, which were published under the title of Tai Chi Composition System: The Analects of Zhao Xiaosheng's Music in 1990. During its sixteen-year of development, the new version was reprinted, entitled Tai Chi Composition System (new edition) in 2006.

5 In order to unify the standard of analysis, both the calculations and the later markings of pitch-class set in this paper are referred to in Allen Forte's List of Pitch-class Sets, only in the case that Zhao's set theory is denoted in the passages regarding the narration of Tai Chi Composition System to compare with Allen Forte's theory.

6 Sancai (三才) indicates the designation of heaven, earth and human beings, which represent three lines in eight trigrams. The topmost line symbolizes heaven, the middle represents human beings, while the bottom means earth.

7 An additional note in the heptatonic scale.

8 See note 6.

9 Because the interval contents of each dyad are the same, the pitch-class sets in the Z relationship are viewed as a unit.

10 The order of class marks in Allen Forte's set list is in reference to the interval vectors, in other word, the pitch class set has more amount ic1 is placed in the front row, if the amounts of ic1 between two pitch classes are same, the sequence refers to ic2, and by analogy. For example, the class mark $3-1[0,1,2]$ contains two ic1 and one ic2, the interval vector of which is $\langle 210000\rangle$, while $3-2[0,1,3]$ contains one ic1, one ic2 and one ic3, the interval vector therefore is $<111000>$. However, the interval vector is no longer the standard of sequence, which is replaced by dissonance ratio. The dissonance ratio is calculated by a formula $\mathrm{R}=\sum / \mathrm{Q}\left(\mathrm{R}\right.$ means dissonance ratio, $\sum$ means the sum of all intervals, and Q means the quantity of notes). Regarding the notation of intervals, Zhao employs U denotes unison (including octave, or fifteenth), P denotes perfect (including fourth and fifth), M denotes major third, $\mathrm{N}$ denotes minor third, $\mathrm{T}$ denotes tri-tone, $\mathrm{S}$ denotes major second, and $\mathrm{D}$ denotes minor second. Then, according to the principle that the intensity of intervals in the front of harmonic series is weaker than those in the back, the coefficients, the numbers of later note of interval in the harmonic series, are added to the interval representations, that are $3 \mathrm{P}, 5 \mathrm{M}, 6 \mathrm{~N}, 7 \mathrm{~T}, 8 \mathrm{~S}$, and $11 \mathrm{D}$ (perhaps the consideration of intensity in the harmonic series borrows the Hindemith's ideal, yet the coefficients are the results of Zhao's mathematical logic). Therefore, the interval sum $\sum$ of $3-1[0,1,2]$ equals $1 \times 8 \mathrm{~S}+2 \times 11 \mathrm{D}$, and $\mathrm{Q}$ equals 3 , the ratio equals $30 \div 3=10$, which is marked as $3-12$ [0, 1,2$]$ due to its twelfth rank. Another example $3-2[0,1,3]$, the result is $(1 \times 6 \mathrm{~N}+1 \times 8 \mathrm{~S}+1 \times 11 \mathrm{D}) \div 3 \approx 8.33$, the class mark is $3-11$ $[0,1,3]$. A reversed situation is obvious in the differences between Forte and Zhao's theories, the first two ranks 3-1 and 3-2 in Fortes' set list become last two ranks. Comparing Fortes' list, Zhao's Tai Chi list of pitch class sets displays more concerns on soundscape and the combination of physical and mathematical demonstration.

11 Schenker's theory is a dominant approach to analyzing tonal music and is viewed as a compositional theory in Temperley's research. Temperley (2011) wrote that works are generated both from the top to down (the order of the Schenkerian hierarchical tree structure) and at some points during the process of composition.

12 Twelve bi hexagrams (十二辟卦), also called twelve news hexagrams, indicate twelve hexagrams located at the bi (辟) position, corresponding to twelve months (LI, 2011). The Chinese character bi means emperor.

13 Per Chung's (1995) explanation, T6 indicates the transposition by ordered pitch-class sixth interval. 


\section{Acknowledgement}

This research is supported by UMRG grant RP038A-17HNE. We would also like to show our gratitude to the Humanity and Social Science Youth foundation of Ministry of Education of China (2019) for their support for the project The Application of I Ching in Modern Music.

\section{References}

ADLER, Jnseph A. Reconstructing the Confucian Dao: Zhu Xi's Appropriation of Zhou Dunyi. 2. ed. New York: The State University of New York Press, 2014. 342 p.

AU, Rebecca Sau-woon. I Ching in the Music of John Cage, Chou Wen Chung and Zhao Xiao Sheng. Doctoral dissertation. The Chinese University of Hong Kong, 2013. Ann Arbor: ProQuest ILC, 2014. 223p.

BIAN, Meng; BIAN Shanyi (Trans.). Zhongguo Gangqin Wenhua zhi Xingcheng yu Fazhan [中 国钢琴文化之兴盛与发展, The Formation and Development of China's Piano Culture]. Beijing: China Music Press, 1996. 181p.

BRUNER, Edward M. Experience and Its Expressions. In TURNER, Victor W. \& BRUNER, Edward M. The Anthropology of Experience. Urbana: University of Illinois Press, 1986. p. 3-32.

CHANG, Chung Yuan. Creativity and Taoism: A Study of Chinese Philosophy, Art and Poetry. London: Singing Dragon, 2011. 239 p.

CHANG, Peter M. Chou Wen-Chung's Cross-Cultural Experience and His Musical Synthesis: The Concept of Syncretism Revisited. Asian Music, Texas, v. 32, n. 2, p. 93-118, 2001.

. Chou Wen Chung and his Music: A Musical and Biogrophical Profile of Cultural Synthesis. Doctoral dissertation. University of Illinois at Urbana-Champaign, 1995. Ann Arbor: A Bell \& Howell Information Company, 1995. 321 p.

Chou Wen-Chung: The Life and Work of a Contemporary Chinese-Born American Composer. Lanham, MD: Scarecrow Press, 2006. 264 p.

CHEN, Chia Chi. Chou Wen-Chung: His Life, the Inspiration of His Musical Language, and an Analytical Study of Windswept Peaks from the Perspective of Chinese Aesthetics. Doctoral dissertation. Cornell University, 2006. Ann Arbor: ProQuest ILC, 2006. 116p.

CHEN, Charles H. I Ching (Yi Jing) and Modern Science: Its Application for the Benefit of Human Society. Bloomington: iUniverse, 2017. 54 p.

CHEN, Hui Ju. East Meets West: The Effect of the Compositional Style of Western Vocal Music on Contemporary Taiwanese Composers. Doctoral dissertation. The University of Maryland, 2008. College Park, MD: The University of Maryland, 2008. 14p.

CHEN, Mingzhi. Bagua shi Zenyang Kongzhi Yinyue de: Zhao Xiaosheng Gangqin Duzou Zuopin Taiji [八卦是怎样控制音乐的一一赵晓生的钢琴曲太极, How to Control Music by Eight Trigrams: Zhao Xiaosheng's Piano Solo Work Tai Chi ]. Music Lover, Shanghai, n.01, p. 4-5, 1988.

CHOU, Wen Chung. A Brief Explanation of Variable Modes, in Chou Wen-chung's own words. Retrieved from http://www.chouwenchung.org/music/chou_on_variable_modes.php Accessed on 4 May, 2017.

CHUNG, Yiu Kwang. I Ching Compositional System: The Symbolism, Structures, and Orderly Sequence of the Sixty-four Hexagrams as Compositional Determinanits. Doctoral dissertation. 
The City University of New York, 1995. Ann Arbor: A Bell \& Howell Information Company, 1995. 116p.

CHUNG, Yiu Kwong. Online interview on 27 July, 2017.

GAO, Heng. Zhouyi Dazhuan Jinzhu [周易大传今注, The Updated Commentories of I Ching]. Jinan: Shandong Qilu Press, 2009. 596p.

GUO, Shunchun. Gudai Shijie Shuxue Taidou Liu Hui [古代世界数学泰斗刘徽, Liu Hui, The Leading Authority of Mathematics in Ancient World ]. Jinan: Shandong Science and Technology Press, 2013. 452p.

JENSEN, Marc G. John Cage, Chance Operations, and the Chaos Game: Cage and the "I Ching". The Musical Times, East Sussex, v. 150, n. 1907, p. 97-102, 2009.

JIN, Jingfang; LV Shaogang. Zhouyi Jiangzuo [周易讲座,The Speech of I Ching]. Changchun: Jilin Unversity Press, 1937. 407p.

KIM, Joo Won. The Development of Contemporary Korean Music with Emphasis on Works of Isang Yun. Doctoral dissertation. The Ohio State University, 2011. Columbus, OH: The Ohio State University, 2011. 87 p.

KOUWENHOWEN, Frank. Mainland China's New Music (3)-The Age of Pluralism. Chime Journal, Leiden, n. 5, p. 76-132, 1992.

KWAN, Chung Ming. Chou Wen-chung's modal system: the Basics. In CHOU WEN-CHUNG MUSIC FESTIVAL: SPECIAL ALBUM: SERIES OF LECTURE, SEMINARS AND COMPOSITION WORKSHOPS “ASIAN MUSIC- WHAT IS THE FUTURE?”, Taipei, 2003. Available at <http:// www.chouwenchung.org/music/modal_system_basics_p4.php. Accessed on 4 May, 2017.

LACH, Donald F. Leibniz and China. Journal of the History of Ideas, Philladelphia, v. 6, n. 4, p. 436-455, 1945.

LAI, Eric C. Modal Formations and Transformations in the First Movement of Chou WenChung's"Metaphors". Perspective of New Music, Seattle, WA, v. 35, n. 1, p. 153-185, 1997.

. The Music of Chou Wen-chung. Farnham, Surrey, UK: Ashgate, 2009. 176 p.

LANG, Xi. Kaichuang de Yidai Zhuanzhe de Yidai Maodun de Yidai - Qingnian Zuoqujia de Chuangzuo, Kuzhong yu Maodun [开创的一代转折的一代 矛盾的一代一一青年作曲家的创作、 苦衷与矛盾, The generation of Innovation, Retroflexion and Contradiction-the Composition, Hardship and Conflict of Youth Composers]. People’s Music, Beijing, n. 6, p.6-8, 1986.

LAU, Frederic. When a Great Nation Emerges: Chinese Music in the World. In YANG Hon Lun \& SAFFLE Michael. China and the West: Music, Representation, and Reception. Ann Arbor, US: University of Michigan Press, 2017. p. 265-310.

LEGGE James (Trans.). The Secred Books of China: The I Ching. New York: Dover Publication, Inc, $1963.448 \mathrm{p}$.

LI, Dingzuo. Zhouyi Jijie [周易集解, The Assembly Commentaries of I Ching]. Beijing: Central Compilation \& Tanslation Press, 2011. 651 p.

LI, Xiaole. Chen Yi's Piano Music: Chinese Aesthetics and Western Models. Doctoral dissertation. The University of Hawai, 2003. Hawai: The University of Hawai Liberary, 2003. 380 p.

LIN, Ginny S. The Tao of Lao Tzu and Yin-Yang in the I Ching's Ten Wings with Special Reference to Contemporary Crises. Doctoral dissertation. California Institute of Integral Studies, 2008. Ann Arbor: ProQuest ILC, 2009. 313 p. 
LIU, Ching Chih. Lun Zhongguo Xinyinyue [论中国新音乐, The Discussion of Chinese new Music]. Shanghai: Shanghai Conservotary of Music Press, 2009. 347 p.

LIU, Ching Chih; MASON, Caroline (Trans.). A Critical History of New Music in China. Hong Kong: The Chinese University Press, 2010. 1000 p.

LOO, Fung Ying; LOO, Fung Chiat. Chinese Science in Piano Pedagogy: Evaluating the Chronicles of Piano Playing Technique with Taichi. Procedia-Social and Behavioral Sciences, Radaweg, Amsterdam, n. 46, p.3102-3106, 2012.

. Tai chi Qi flow in the kinematic process of piano playing: An application of Chinese science. World Applied Sciences Journal, Deira, Dubai, v. 21, n. 1, p.98-104, 2013.

LU, Bai; PANG, Petti T; WOO, Newton H. The Yin and Yang of Neurotrophin Action. Nature Reviews Neuroscience, London, v. 6, n. 8, p. 603-614, 2005.

MA, Qianyue. Jiexi Zhao Xiaosheng Taiji Zuoquxitong dui Yingaocailiao de Kongzhi [解析赵晓生 太极作曲系统对音高材料的控制, An Analysis of Pitch Materials controlled by Zhao Xiaosheng's Tai Chi composition system]. Master thesis. Xi'an Conservatory of Music, 2013. Xi'an: Xi'an Conservatory of Music, 2013. 69 p.

RAO, Nancy Yunwha. Hearing Pentatinicism Through Serialism: Integrating Different Traditions in Chinese Contemporary Music. Pespective of New Music, Seattle, WA, v. 40, n. 2, p. 190-231, 2002.

RYAN, James A. Leibniz' Binary System and Shao Yong's "Yijing”. Philosophy East and West, Hawai, v. 46, n. 1, p.59-90, 1996.

SHI, Yang. Zhao Xiao Sheng Taiji Zuoquxitong Xiandai Siwei Tansuo [赵晓生太极作曲系统 现代思维探索, A Modernity Thinking Exploration on Zhao Xiaosheng's Tai Chi Composition System]. Master thesis. Central China Normal University, 2012. Wuha: Central China Normal University, 2012. $42 \mathrm{p}$.

TEMPERLEY, David. Composition, Perception, and Schenkerian Theory. Music Theory Spectrum, New York, v. 33, n. 2, p.146-168, 2011.

TSAI, Yi Chuan. Taiwanese Traditional Musical Idioms Meet Western Music Composition: An Analytical and Pedagogical Approach to Solo Piano Works by Tyzen Hsiao. Doctoral dissertation. The University of Southern Mississippi, 2017. Hattiesburg: The Aquila Digital Community, 2017. $74 \mathrm{p}$.

WANG, Anguo. “Xinchao” Yinyue - Yiduan Teding de Lishi Wenhua Guocheng [“新潮”音 乐——段特定的历史文化过程, “New Wave” Music - A Special historal and cultural process]. Literature \& Art Studies, Beijing, n. 1, p. 62-72, 1988.

WANG, Zhenya. Zhongguo Zuoqujifa de Yanbian [中国作曲技法的衍变, The Evolution of Chinese Compositional Techniques]. Beijing: Central Conservotary of Music Press, 2004. 290 p.

WANG, Zidong. A Study on the Constructive Modes of Pitch System of Chou Wen Chung's Music. Doctoral dissertation. Shanghai Conservatory of Music, 2013. Shanghai: Shanghai Conservatory of Music, 2013. 148 p.

WU, Zong Jie; HAN, Chun Yan. Pedagogy Toward Diversity: A Cross-Cultural Approach to Historicizing the Present. In PEREYRA, Miguel A. \& FRANKLIN, Barry M. (Ed.). Systems of Reason and the Politics of Schooling: School Reform and Science of Education in the Tradition of Thomas S. Popkewitz. New York: Routledge, 2014. p. 180-206.

XU, Weiyu; LIANG Yunhua (Ed.) Lvshi Chunqiu Jishi [吕氏春秋集释, The Commentories of Lv's Spring and Autumn Annals]. Beijing: Zhonghua Book Company, 2016. 642p. 
ZENG, Shi Qiang. Yijing de Aomi [易经的奥秘, The Mystery of I Ching]. Xi'an: Shanxi Normal University Press, 2009. 236 p.

XUE, Ke; LOO, Fung Ying. Reminiscing Crashing Waves and Romanticism in Zhao Xiaosheng's Fisherman Song. Malaysian Journal of Performing and Visual Arts, Kuala Lumpur, v. 3, p. 7-30, 2017

ZHAO, Jingxuan. Per Nørgård Yijing zhi Zuopin Fenxi yu Yishu Fengge de Duoyuanxing Tantao [皮尔. 诺加德易经之作品分析与艺术风格的多元性探讨, The Analysis of Per Nørgård's Yijing and its multi-feature]. Master thesis. Central Conservotary of Music, 2014. Beijing: Central Conservotary of Music, 2014. 18 p.

ZHAO, Wenbin. Lun Wuxing zhong Zhuti de Goucheng jiqi Fazhan Shoufa [论五行中主题的构 成及其发展手法, On the Construction of Themes and Development of “Five Elements"]. Journal of Tianjin Conservotary of Music (Sounds of Nature), Tianjin, n. 2, p. 50-58, 2010.

ZHAO, Xiaosheng. Taiji Zuoqu Xitong: Zhao Xiaosheng Yinyue Lunji [太极作曲系统: 赵晓生 音乐论集, Tai Chi Composition System: the Analects of Zhao Xiaosheng’s Music]. Guangzhou: Guangzhou Branch, Popular Science Press, 1990. 394 p.

ZHAO, Xiaosheng. Tai Chi Composition System(new edition). Shanghai: Shanghai Music Press, 2006. 323 p.

ZHAO, Xiao Sheng. Interview on 31 October, 2016. Shanghai, China.

ZHOU, Jinmin. New Wave Music in China. Doctoral dissertation. University of Maryland Baltimore County, 1993. Ann Arbor: A Bell \& Howell Information Company, 1993. 327 p.

ZHOU, Qinru. Yinyue Shenceng Jiegou de Jianhua Huanyuan Fenxi [音乐深层结构的简化还原分 析一一克分析法评介, The Simplicity and Reduction Analysis of Musical Profound StructureCommentary to Schenkerian Analysis]. Music Research, Beijing, n. 2, p. 25-36 \& 81, 1987.

ZHOU, Weimin. 20 Shiji Zhongguo Yinyue Chuangzuo de Huigu yu Sikao [20世纪中国钢琴音乐 创作的回顾与思考, The Rethinking about Chinese piano compositions in $20^{\text {th }}$ century]. Chinese Music, Beijing, n. 2, p. 116-121, 2007.

ZHU, Jianer. He’erbutong ------Wuchongzou “He” Chuangzuo Zhaji [和而不同——五重奏《和》 创作札记, Combinition with Difference-Compositional Notes of He for Quintet]. Music Arts Journal of Shanghai Conservotary of Music, Shanghai, n. 1), p. 52-55, 1995.

Ke, Xue. Associate professor at College of Humanities, Beibu Gulf University. Her research interest includes Chinese contemporary music, Chinese piano music and performance practice. Her publication includes Zhao Xiaosheng's piano compositions and Chinese piano music.

Fung Ying, Loo. Associate professor of Cultural Centre, University of Malaya. She is a composer and pianist with Malaysian Dama Orchestra. Her research interest includes Chinese music and musical theatre. Her publication includes Taichi and its application on piano playing skills, and Malaysian Chinese music traditions. 